\title{
Microstructure-sensitive Estimation of Small Fatigue Crack Growth in Bridge Steel Welds
}

\author{
Hao Yuan ${ }^{1}$, Wei Zhang ${ }^{2 *}$, Gustavo M. Castelluccio ${ }^{3}$, Jeongho Kim ${ }^{4}$, Yongming Liu ${ }^{5}$
}

\begin{abstract}
A probabilistic finite element model is implemented to estimate microstructurally small fatigue crack growth in bridge steel welds. Simulations are based on a microstructure-sensitive crystal plasticity model to quantify fatigue indicator parameters (FIPs) at the slip system level and a fatigue model that relates FIPs to fatigue lives of individual grains. Microstructures from three weld zones, namely, fusion zone (FZ), heat affected zone (HAZ), and base metal (BM), are constructed based on their microstructural attributes such as grain morphology, size, and orientation. Statistical volume elements (SVEs) are generated and meshed independently for the three welding zones. Each grain within the SVEs is divided into several slip bands parallel to crystallographic planes. During the loading process, cracks nucleate at the slip bands (SBs) with the largest FIP next to the free surface. The crack extension path is assumed to be transgranular along SBs and the number of cycles required to crack the neighbor grain is calculated by the corresponding FIP-based crack growth rate equation. The simulation process is carried out using ABAQUS with a user defined subroutine UMAT for crystal plasticity. After the calibration of the constitutive model and irreversibility parameters, numerical simulations for small crack growth in three zones are presented. The crack length vs. the predicted fatigue resistance shows significant differences in the mean values and variability among the three weld zones.
\end{abstract}

Keywords: high cycle fatigue (HCF); small fatigue crack; probabilistic; microstructure; crystal plasticity

\footnotetext{
${ }^{1}$ Graduate Student, Dept. of Civil and Environmental Engineering, University of Connecticut, Storrs, CT 06269, USA

$2^{2 *}$ Assistant Professor, Dept. of Civil and Environmental Engineering, University of Connecticut, Storrs, CT 06269, USA Contact: wzhang@,uconn.edu

${ }^{3}$ Research Senior Lecturer, School of Aerospace, Transport and Manufacturing, Cranfield University, Cranfield, MK43 0AL, UK

${ }^{4}$ Associate Professor, Dept. of Civil and Environmental Engineering, University of Connecticut, Storrs, CT 06269, USA

${ }^{5}$ Professor, Sch. for Engineering of Matter, Transport and Energy, Arizona State University, Tempe, AZ 85281, USA
} 


\section{INTRODUCTION}

Coastal and offshore infrastructure is constantly evolving to span over increasingly larger water bodies and to exploit natural resources in remote areas. To mention a few examples, the challenge is to build economic and sustainable coastal bridges, ships, offshore floating structures, and subsea pipelines that can endure decades under harsh environments and unforeseen conditions. These structures usually employ welding as a method to connect metallic structural members, mainly made of high strength low alloy steel (HSLA) including bridge steel. Certainly, open or closed ribs are often welded to the deck plate in orthotropic deck design of bridges, ships or offshore structures, for enhancing the bending resistance of steel plates to carry lateral loads [13]. These joints resist cyclic deformations or repetitive service loads from heavy vehicles, hurricane-force wind, and destructive waves that can initiate and propagate fatigue cracks. In addition, welding procedures introduce material heterogeneity, mesoscale defects, residual stresses, and geometric distortions that are detrimental to fatigue and fracture resistance. The vast number of welds in orthotropic decks have raised safety concerns regarding localized fatigue failure [4]. However, design codes for fatigue failure are usually based on nominal stress approaches that neglect local stress raisers, material heterogeneity, and weld profiles.

Many local approaches for fatigue assessment of welded joints have been developed since 1930s to estimate the fatigue crack propagation starting from discontinuities and notches [5-7]. The validity of these approaches depends on a preexisting defect that resembles a crack-like shape, which is not always present in current high-quality welding processes and post-weld improvement techniques. Certainly, the fatigue crack initiation phase usually dominates fatigue lives, especially in the high cycle fatigue $(\mathrm{HCF})$ regime [8], whereas fatigue cracks usually initiate in welded toe under elastic nominal stresses below the fatigue limit of the base metal. Approaches discussed 
above are also unable to capture the intrinsic microstructural variability of fatigue failure due to the implicit assumption of isotropic homogeneous materials $[9,10]$.

Recent advances on local approaches have attempted to predict the number of cycles to nucleate and propagate small fatigue cracks in base and welded metals [5,11-13]. Fricke [7] and Remes [14] highlighted that most frameworks seldom offer explicit simulation of small fatigue cracks meandering through weld microstructures, a process that strongly depends on microstructural attributes and mesoscale irreversible processess (dislocation production and localization, micro-crack initiation along slip bands and further crack growth by local slip mechanisms at the crack tip). Therefore, the evaluation and prediction of the early fatigue behavior in weld requires microstructure-sensitive approaches.

Microstructure-sensitive models for fatigue crack initiation and propagation have been a matter of active research for decades [15-17], with particular focus on isotropic and homogeneous polycrystalline alloys for aerospace applications (e.g., Ni or Ti alloys). However, steel welds with strong gradients in their polycrystalline structure have received little attention. Welds typically present roughly three zones — base metal (BM), heat affected zone (HAZ) and fusion zone (FZ) — that may have different phases, grain size and morphology, which impact directly mechanical response [18-20]. Therefore, small crack nucleation and propagation methods developed for isotropic and homogeneous materials may be applied to the weld microstructure as long as the microstructural attributes of each zone are taken into account.

Mesoscale methods based on crystal plasticity are among the more effective approaches to link microstructure to component level response under complex loading conditions. At micro- and meso-scales, the microstructure plays a key role in the evolution of micromechanical stresses and strains and that leads to microstructurally small cracks (MSCs). Random grain morphology and 
size, crystallographic orientation, inclusions, voids, and other microstructural features result in local anisotropy and highly heterogeneous stresses and strains.

Simple mesoscale models for MSC such as Tanaka-Mura [15], Miller-Hobson [21], Navarro and de los Rios [22] are still commonly employed in computational models, but they are limited in rendering realistic microstructures. Recent developed microstructure-sensitive models based on fatigue indicator parameters (FIPs) [23] are a promising tool to describe both MSC nucleation and growth. Several FIPs, such as those based on accumulated plastic strain and dislocation density [24-26], energy dissipation [27,28], averaged effective strain and tensile stress [29,30], are based on non-local variables different for each damage mechanism [31]. Due to the complexity of cyclic microplasticity and damage formation in $\mathrm{HCF}$, the FIPs provide a computable parameter to quantify fatigue damage at a microstructural length scale for engineering applications.

In the present study, a probabilistic framework of small fatigue crack simulation is employed to quantify and differentiate the potential fatigue damage in steel welds for bridges. We employ a microstructure-sensitive fatigue model based on non-local crystallographic FIPs to estimate the number of cycles required to grow fatigue cracks along BM, HAZ, and FZ. The paper is organized in following sections: Section 2 introduces the 2D microstructure-sensitive computational model and FIP formulations. Section 3 discusses statistical volume elements (SVEs) for microstructures of each weld zone, including building crystal plasticity model, generation and mesh of Voronoi grain structure, and boundary conditions. Section 4 presents the framework implementation, calibration, and results. The framework is implemented in ABAQUS [32] with Python scripts for the whole process and user defined subroutine UMAT for crystal plasticity. The verification of the non-local FIP as a mesoscale fatigue driving force is carried out for single body center cubic (BCC) crystal structure. Afterwards, a calibration of irreversibility parameters and prediction assessments 
are presented along with comparisons of crack length $(a)$ vs. predicted number of cycles $(N)$, and crack growth rate $d a / d N$ vs. $a$ for each weld zone. Section 5 and 6 discusses the validity of the results and summarize conclusions.

\section{SMALL FATIGUE CRACK MODEL FOR WELDS}

The total fatigue life in polycrystals can be partitioned into four physically-based regimes: nucleation $\left(10^{-7} \mathrm{~m} \sim 10^{-5} \mathrm{~m}\right)$, microstructurally small crack (MSC, $\left.10^{-7} \mathrm{~m} \sim 10^{-5} \mathrm{~m}\right)$, physically short crack (PSC, $\left.10^{-5} \mathrm{~m} \sim 10^{-4} \mathrm{~m}\right)$, and long crack $\left(\mathrm{LC},>10^{-3} \mathrm{~m}\right)$ [33]. These regimes are arbitrary constructions that have been historically useful to correlate macroscopic crack growth rates with crack length. Indeed, the physics that dominate MSC and PSC regimes are identical, but they differ in the number of grains controlling crack growth. Thus, some approaches combine both regimes:

$$
N_{f}=N_{n u c}+N_{m s c}+N_{p s c}+N_{l c}=N_{n u c}+N_{m s c \mid p s c}+N_{l c}
$$

It is noteworthy that, for high-cycle fatigue (HCF) loading conditions and high-strength materials, up to $90 \%$ of a component's fatigue life can be determined by the phase of crack nucleation and the propagation of MSC [34]. Following experimental evidence in steel [35], we assume that MSCs are transgranular and are driven by the cyclic plasticity in the bulk of the grains. This assumption allows us to employ the microstructure-sensitive framework developed by Castelluccio and Mcdowell [33,36-38] and Fatemi and Socie's FIP to assess fatigue crack growth through weld microstructure.

\subsection{Prediction of fatigue crack nucleation based on FIPS}

Well-controlled and high-quality welding or post-weld treatment often results in low residual stresses and very few weld defects such as mesoscale inclusions and pores. Instead, crack nucleation usually occurs due to the irreversible accumulation of damage along crystallographic 
planes (so called Stage I fatigue). Thus, we define crack nucleation as the number of cycle to fully develop a crack within the first grain. Following experimental findings [39], only crystallographic slip bands are considered as the mechanism that nucleated cracks in welds. According to [36], FIP proposed by Fatemi and Socie [40] can be used as an effective surrogate measure for cyclic crack tip displacement range $(\triangle \mathrm{CTD})$ under the mixed mode loads in crystallographic cracks, i.e.

$$
\operatorname{FIP}^{(\alpha)}=\frac{\Delta \gamma_{p}^{(\alpha)}}{2}\left[1+k \frac{\sigma_{n}^{(\alpha)}}{\sigma_{y}}\right]
$$

where $\Delta \gamma_{p}^{(\alpha)}$ is the cyclic plastic shear strain range on the $\alpha$ slip system, $\sigma_{n}^{(\alpha)}$ is the peak stress normal to the slip plane of this slip system, $\sigma_{y}$ is the reference strength, $k$ is a constant, usually between 0 and 2, but for steel weld we choose $k=1$ according to [41].

One of the most challenging aspects of studying the mechanical response of HSLA steels is the various phases the may arise during thermomechanical treatments like welding $[6,35]$. To overcome these difficulties, this work assumes that weld zones contain only a stable ferritic phase with BCC crystalline structure. As discussed later on, this assumption should not have a major impact on the fatigue predictions since experimental evidence indicates that cracks nucleate and propagate along persistent slip bands (PSBs) in ferritic grains in the three weld zones [35,39]. Thus, FIP values are averaged over predefined SBs, which subdivide a grain into layers that are parallel to the prime slip system. Each SB has a nominal thickness of two elements and transgranular crystallographic failure is assumed to occur along plastic deformation localized in these bands.

The mesoscale fatigue model defines the crack nucleation period $N_{n u c}$ as the minimum number of cycles required to crack the first grain and follows the semi-empirical relation [15],

$$
N_{\text {nuс }}=\frac{\alpha_{g}}{d_{g r}}\left(\mathrm{FIP}_{\text {meso }}^{(\alpha)}\right)^{-2}
$$


in which $\operatorname{FIP}_{\text {meso }}^{(\alpha)}$ is the SB-averaged FIP for $\alpha$ slip system, $\alpha_{g}$ is an irreversibility coefficient, and $d_{g r}$ is length scale of the microstructure, such as the order of the grain size, which can be calculated by revising Eq. (24) in [36] for 2D microstructure,

$$
d_{g r}=D_{s t}+\omega D_{n d}
$$

where $D_{s t}$ is the length of the band in the current grain and $D_{n d}$ is the length of intersecting bands in the adjacent grain. The disorientation factor $\omega$ is calculated according to [36] and is zero for most grains since the misorientation with neighbor grains exceeds $20^{\circ}$ based on grain cluster with random crystal orientation.

Based on prior research [36] and convergence studies not included for the sake of brevity, our model shows that two computational loading cycles are enough to estimate the dominant shape of the stress and plastic strain range fields that contribute to crack formation, i.e. at the time the FIP is stable for a long cyclic life under HCF. Of course, the number of computational cycles required depends on the ability of the constitutive model to reach saturation and the desired accuracy of the fatigue estimation. In this case, we attempt to roughly quantify fatigue evolution in different zones of welds rather than an accurate prediction on each zone.

\subsection{MSC propagation by microstructure-sensitive crack growth equation}

The MSC crack growth rate can be understood as the net number of dislocations emitted from a crack tip after a cycle, or equivalently the $\triangle \mathrm{CTD}$. As shown by Castelluccio [33], the SBaveraged mesoscale FIP can serve as a more efficient fatigue indicator for MSC growth, i.e.

$$
\left.\frac{d a}{d N}\right|_{m s c} ^{(\alpha)}=\phi\left\langle A \frac{d_{g r}}{d_{g r}^{r e f}} \operatorname{FIP}_{m e s o}^{(\alpha)}-\Delta \mathrm{CTD}_{t h}\right\rangle
$$

where $\phi$ is a measure of the mechanical irreversibility at the crack tip process zone (typically 0.01 $\sim 0.1)$ and $\Delta \mathrm{CTD}_{\text {th }}$ is a threshold that recognizes a minimum required $\Delta \mathrm{CTD}$ for dislocation 
emission (on the order of the Burgers vector). In between the Macaulay bracket, $A=2 \mu \mathrm{m}$ is a scaling constant that correlates FIP meso with $\triangle \mathrm{CTD}$, and $d_{g r}^{r e f}$ is a reference distance that nondimensionalizes the grain size effect (mean grain size).

The simplification of grain-by-grain crack growth requires a strategy to predict the evolution of the FIP as the crack growth progresses inside a grain. When computing MSC crack growth rate in Eq. (5), we assume that the FIP depends on the crack length within a grain as stated in Eq. (6). Such an equation should be understood as a mesoscale self-similar dependence of the fatigue driving force on the fraction of grain that has been fractured. Compared to sub-grain element-byelement growth method, the grain-by-grain approach based on SB-averaged FIP can provide statistically-equivalent predictions with significantly lower computational effort [36].

$$
\operatorname{FIP}_{\text {meso }}^{(\alpha)}=\operatorname{FIP}_{0}^{(\alpha)}\left[1-R_{G B}\left(a / D_{s t}\right)^{m}\right]
$$

In Eq. (6), $\mathrm{FIP}_{0}$ is the FIP value before any crack growth occurs in a grain; $R_{G B}$ and $m$ can be taken as a resistance measure of the grain boundary (GB) to the crossing crack [42]. Although these parameters depend on complex GB conditions such as twist/tilt angle, grain morphology and other material properties, for the current study $R_{G B}$ is treated as a deterministic parameter that characterizes the mean value of mesoscale crack growth. Regarding the parameter $m$, Table 1 and Fig. 1(a) present various alternatives to represent the evolution of the FIP as a crack grows along a SB within a grain. Case (1) corresponds to a constant FIP as the crack progress throughout a grain; Case (2) indicates the constant influence form the GB independent of the crack length within the grain; Case (3) and (4) assume linear and parabolic decay of the FIP as the crack grows within the grain due to the influence of GBs. Accordingly, the number of cycles needed to fully crack a grain (after nucleating a crack in the first grain) can be calculated by analytically integration of 
Eqs. (5) with Eq.(6), and the results are listed in Table 1. Here, $C\left(1-R_{G B}\right)>\Delta \mathrm{CTD}_{\text {th }}$ is assumed to evaluate the Macaulay bracket in Eq. (5).

Table 1 Different self-similar evolutions of FIPs inside grain and corresponding cycle number $N$ after integrating Eq. (5).

\begin{tabular}{c|c|c|c}
\hline Case & Condition & $\operatorname{FIP}_{\text {meso }}^{(\alpha)}$ & $\left.N\right|_{m s c} ^{(\alpha)}\left(C=A \frac{d_{g r}}{d_{g r}^{r e f}} \operatorname{FIP}_{0}^{(\alpha)}\right)$ \\
\hline$(1)$ & $R_{G B}=0$ & $\operatorname{FIP}_{0}^{(\alpha)}$ & $\frac{D_{s t}}{\phi}\left(C-\Delta \mathrm{CTD}_{t h}\right)^{-1}$ \\
\hline$(2)$ & $R_{G B} \neq 0, m=0$ & $\left(1-R_{G B}\right) \mathrm{FIP}_{0}^{(\alpha)}$ & $\frac{D_{s t}}{\phi}\left[C\left(1-R_{G B}\right)-\Delta \mathrm{CTD}_{t h}\right]^{-1}$ \\
\hline$(3)$ & $R_{G B} \neq 0, m=1$ & $\left(1-R_{G B} \frac{a}{D_{s t}}\right) \mathrm{FIP}_{0}^{(\alpha)}$ & $\frac{D_{s t}}{\phi C R_{G B}} \ln \frac{C-\Delta \mathrm{CTD}_{t h}}{C\left(1-R_{G B}\right)-\Delta \mathrm{CTD}_{t h}}$ \\
\hline$(4)$ & $R_{G B} \neq 0, m=2$ & {$\left[1-R_{G B}\left(\frac{a}{D_{s t}}\right)^{2}\right] \operatorname{FIP}_{0}^{(\alpha)}$} & $\frac{D_{s t} \tanh ^{-1}\left[\left(C R_{G B}\right)^{1 / 2}\left(C-\Delta \mathrm{CTD}_{t h}\right)^{-1 / 2}\right]}{\phi\left(C R_{G B}\right)^{1 / 2}\left(C-\Delta \mathrm{CTD}_{t h}\right)^{1 / 2}}$ \\
\hline
\end{tabular}

Note: We consider $m=0,1$, and 2 to demonstrate the variability that can be attributed to the mesoscale crack growth evolution. For $m \geq 3$, the integration of Eq. (5) becomes significantly more complicated.

Fig. 1(b) compares MSC grain lives, $N$, for different FIP evolutions in Table 1, normalized by $\mathrm{FIP}_{0}$ (Case (1)) and assuming that $R_{G B}=0.5$ is representative of the average GB resistance. The normalized grain life drops rapidly when $C=A \frac{d_{g r}}{d_{g r}^{r e f}} \operatorname{FIP}_{0}^{(\alpha)}$ increases from 2 to 4; after that, the normalized grain life stabilize to a constant, such as 1.25 for Case (4). Fig. 1(b) shows that the number of cycles to crack a grain is bounded by Cases (1) and (2), with the former being more conservative. Furthermore, a higher exponent $m$ results in the curve closer to that for Case (1); for 
$m \geq 3$, these trends holds but are not drawn for consistency with Table 1. In summary, these results suggest that the details of the parameterization in Eq. (6) affect the most the near fatigue threshold regime $\left(C \approx \Delta \mathrm{CTD}_{t h}\right)$. Lives for higher cyclic deformation tend to saturate and only differ in a scaling factor in different cases.

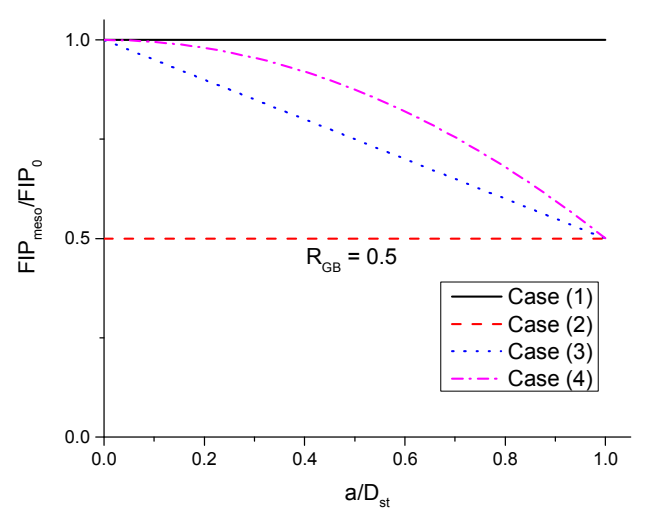

(a)

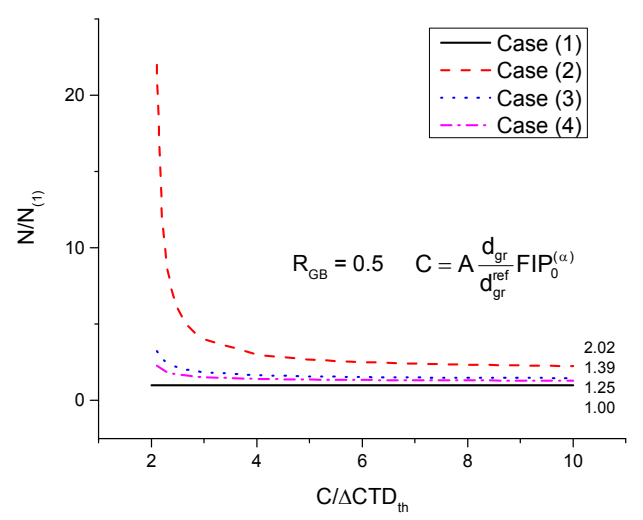

(b)

Figure 1. Normalized sub-grain FIP variation (a) and corresponding fatigue life of a grain (b). When incorporated into the whole framework, the Macaulay bracket in Eq. (5) is evaluated at the beginning of the crack starting with the $\mathrm{FIP}_{0}$. If $C\left(1-R_{G B}\right)>\Delta \mathrm{CTD}_{\text {th }}$, Case (1), (3) or (4) can be used; if $C>\Delta \mathrm{CTD}_{\text {th }}$ and $C\left(1-R_{G B}\right)<\Delta \mathrm{CTD}_{\text {th }}$, Case (1) will be used instead and the cracks stop growing at the next boundary; if $C \leq \Delta \mathrm{CTD}_{\mathrm{th}}$, crack is arrested at the current tip location.

Inspired by Fig. 1(b), a simple scheme is adopted to calculate $N$ for different cases while $R_{G B}$ $=0.5$. Assuming that $C / \Delta \mathrm{CTD}_{\text {th }}$ is outside of the range between 2 to 3 , then conservatively, all $N$ can be evaluated as Case (1) firstly and multiplied by the stable normalized $N$ (1.39 for Case (3), and 1.25 for Case (4)) to get the fatigue life considering the sub-grain FIP variation. Therefore, in the following sections, all simulations are performed under Case (1). 
Since the dominating transgranular MSC controls fatigue life, only one crack is assumed to nucleate per realization; after nucleation, the crack extends to the next grain along the closest SB that intersects with the crack tip elements, while at most time the SB has the minimum fatigue life.

\section{WELD ZONE MICROSTRUCTURES}

\subsection{Voronoi tessellation for different weld zones}

Our modeling framework relies on the explicit representation of grain morphology and a mesoscale domain to compute a microstructure-sensitive driving force that controls MSC growth. As shown by Castelluccio and McDowell [43], an adequate mesoscale domain helps mitigating mesh sensitivity and reduces the need for fine meshes. Furthermore, Sauzay et al. [44] showed minimum differences in the distributions of internal state variables between coarse cubic grains and refined conformal meshes; this characteristic is particularly relevant for transgranular fatigue failure. Thus, we recreate synthetic microstructures generated with a Poisson-Voronoi tessellation algorithm, which has been extensively used for modeling polycrystalline material. An open-source quasi-random polycrystal generator Neper [45] is used to distribute grain seeds that builds the microstructure together with a Python script that regulates the grain morphology and subdivides the microstructure in SBs.

Fig. 2(a) compares synthetic and experimental microstructures from a single-pass weld [46]; grain size in the synthetic microstructure is enlarged for clarity. From each weld zone with in Fig. 2(a), SVEs of grain aggregates are sampled with size according to commonly used characteristic transition length to PSC or LC and drawn schematically in Fig. 2 (b) with predefined SBs (or potential locations of PSBs) shown as dark/white lines. These microstructures represent different zones of the weld profile of shield metal arc weld (SMAW) [46] which is a typical process in bridge welding. Compared to the grains in BM, the grains in HAZ may be coarser (CGHAZ) or 
finer (FGHAZ) due to the recrystallization and subsequent thermally activated grain growth processes. Since larger grains are usually more prone to fatigue cracking than smaller grains [47], this work assumes that the HAZ is fully composed of coarse ferritic grains (worse scenario). Grains in the FZ have columnar shape due to the direction heat flow in the solidification process. Similar grain morphologies were found in experiments $[46,48]$.

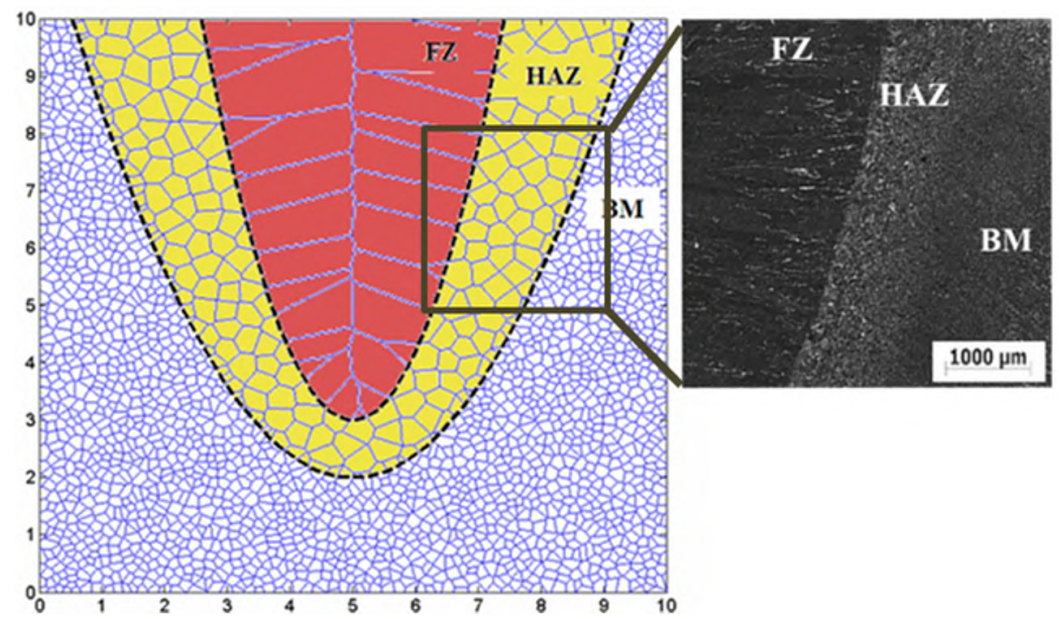

(a) Numerical generation and a comparative photo of a cross-sectional-bead-shape weld profile of single-pass SMAW

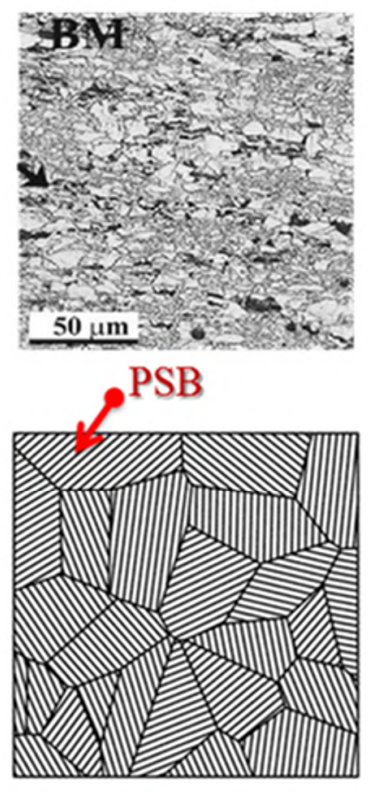

$\mathrm{BM}$
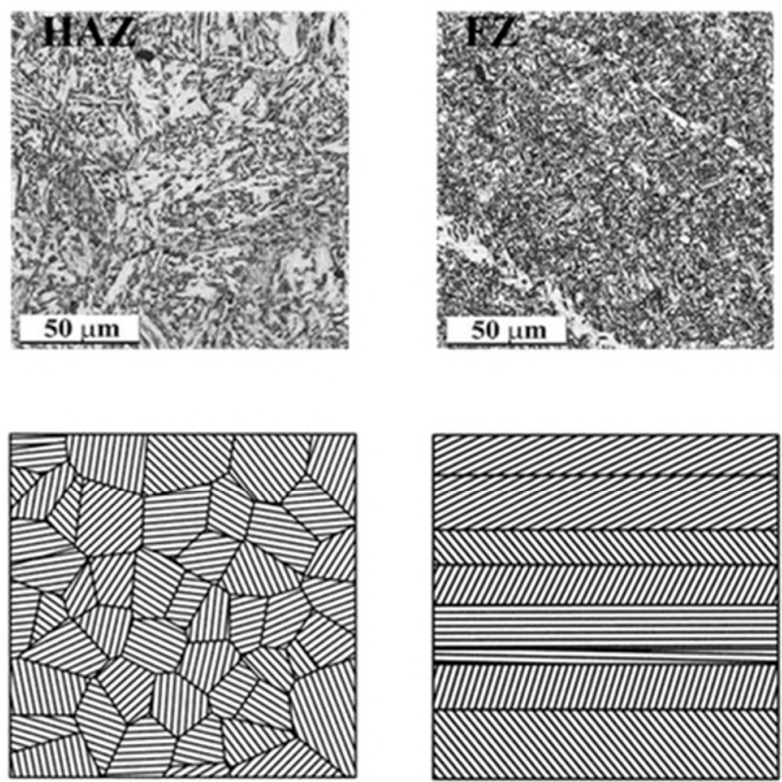

HAZ

$0.5 \mathrm{~mm} \times 0.5 \mathrm{~mm}$

$70 \mu \mathrm{m}$ grain

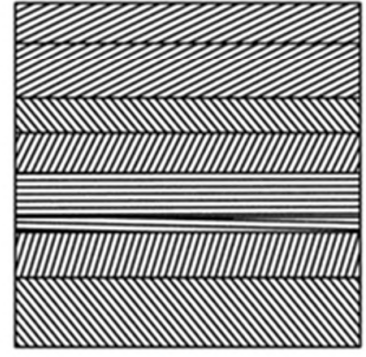

FZ

$20 \mu \mathrm{m}$ grain

$0.1 \mathrm{~mm} \times 0.1 \mathrm{~mm}$ 
(b) Schematic SVEs with typical grain size and morphology from SMAW

Figure 2. Schematic SVEs with typical grain size and morphology from SMAW. (Black and white lines in SVE represent the mesoscale domains (SBs) in which mean FIPs are computed. Experimental images are from an Open Access $\left.\operatorname{article}^{1}[48]\right)$

\subsection{Grain property assignment, boundary conditions, and mesh of SVE}

Each grain corresponds to a crystal with cubic elastic properties, a predefined crystallographic orientation, and impenetrable grain boundaries. In 2D implementations of crystal plasticity, the slip systems degrade to a planar mode that accommodates plane stress/strain state. To reproduce the stochastic effect of grains on fatigue damage, each grain has a random prime slip orientation defined by an angle $\theta$ subtended from the $x$ geometrical axis, where $0^{\circ} \leq \theta<360^{\circ}$ (non-directional solidification is assumed). A uniform distribution is considered for grain orientations, which assumes there is no crystallographic texture.

Periodic boundary conditions (PBCs) are imporse to reproduce the constraint of the bulk material from a large domain. Furthemore, we perform multiple microstructural realizations of SVEs with a finite number of grains to estimate the distributions of true representative volume elements (which are much larger and computationally unfeasible). Note that a true representative volume element (RVE) for FIP would require thousands of grains [43]. Following the approach by $\mathrm{Wu}$ [49], we employ PBCs on finite element meshes built with CPE3 plane strain element generated with Neper and ABAQUS.

\footnotetext{
${ }^{1}$ This Open Access article is distributed under the terms of the Creative Commons Attribution Non-Commercial License which permits unrestricted non-commercial use, distribution, and reproduction in any medium provided the original work is properly cited.
} 


\subsection{Crystal plasticity finite element method (CPFEM)}

We employ a crystal plasticity model introduced by Huang [50], but modified to account for Bauschinger effects. Inelastic crytal deformation arise from crystalline slip as a result of dislocation nucleation and glide. The shear rate $(\not)$ follows a power law expression for each slip system $\alpha$,

$$
\mathcal{L}^{(\alpha)}=\mathcal{L}^{(\alpha)} \operatorname{sgn}\left(\tau^{(\alpha)}-B^{(\alpha)}\right)\left|\frac{\tau^{(\alpha)}-B^{(\alpha)}}{g^{(\alpha)}}\right|^{n}
$$

where $\tau$ is shear stress, $g$ is the drag strength, $\&$ is the reference shear strain rate, $B^{(\alpha)}$ is the back stress that accounts for Bauschinger effect, and $n$ is the strain rate sensitivity parameter (a larger value of $n$ ensures the rate independent case, such as $n=50$ ). The values of these material properties are listed in Table 2.

The drag strength rate for each slip system is given by,

$$
g \mathcal{E}^{(\alpha)}=\sum_{\beta} h_{\alpha \beta} \mathcal{\alpha}^{(\beta)}
$$

where the matrix $h_{\alpha \beta}$ contains the hardening modulus for each slip system, $h_{\alpha \alpha}$ is known as selfhardening while $h_{\alpha \beta}(\alpha \neq \beta)$ is known as latent hardening.

Our approach modifies the hardening modulus employed by Huang [50] and considers three stages (Equation 9) of hardening in crystalline materials [51]. The self and latent hardening coefficients depend on the shear strains $\gamma^{(\alpha)}$ of all slip systems as follows:

$$
\begin{aligned}
& h_{\alpha \alpha}=\left\{\left(h_{0}-h_{s}\right) \operatorname{sech}^{2}\left[\frac{\left(h_{0}-h_{s}\right) \gamma^{(\alpha)}}{\tau_{s}-\tau_{0}}\right]+h_{s}\right\} G\left(\gamma^{(\beta)} ; \beta \neq \alpha\right) \\
& h_{\alpha \beta}=q h_{\alpha \alpha}(\beta \neq \alpha) \\
& G\left(\gamma^{\beta} ; \beta \neq \alpha\right)=1+\sum_{\beta \neq \alpha} f_{\alpha \beta} \tanh \left(\gamma^{(\beta)} / \gamma_{0}\right)
\end{aligned}
$$


where $h_{0}$ is the initial hardening modulus, $\tau_{0}$ is the initial yield stress, $\tau_{s}$ is the saturation stress, $g^{(\alpha)}$ is the total shear strain in system $\alpha, h_{s}$ is the hardening modulus during stage I deformation, $f_{\alpha \beta}$ is the interaction strength between slip system $\alpha$ and $\beta$, and $\gamma^{(\beta)}$ is the total shear strain in slip system $\beta$.

A nonlinear hardening-recovery evolution rule is set for the back stress rate in accordance with Ref. [52],

$$
B^{(\alpha)}=c \gamma^{(\alpha)}-d B^{(\alpha)}\left|2 \alpha^{(\alpha)}\right|
$$

where $c$ and $d$ are material parameters identical for all slip systems. The fading memory term $d B^{(\alpha)}\left|\mathcal{L}^{(\alpha)}\right|$ introduce the Bauschinger effect of materials.

The above model is implemented in ABAQUS using a user defined subroutine UMAT. Different material parameters for each weld zone can be calibrated considering polycrystal or single crystal response (monotonic or cyclic, shear or normal) along with optimization algorithms [53]. Since the present study focuses on the mesoscale effects of ferritic grains (which dominate fatigue), the same material parameters are employed for three weld zones, and the values are adopted from HSLA 50 in the literature [52]; material parameters are summarized in Table 2. The constitutive model assumes that slip occurs along three families of slip systems for BCC crystal, i.e. $\{110\}<111>,\{112\}<111>$, and $\{123\}<111>$. However, only $\{110\}<111>$ slip systems are assumed to nucleate cracks due to their highest closest atomic density [54].

To validate the proposed modeling scheme, Fig. 3 compares the cyclic stress-strain curves from simulations and experimental data from the literature [52]. Simulations consider a SVE of $400 \mu \mathrm{m} \times 400 \mu \mathrm{m}$ in size, 150 grains, with $1386 \mathrm{CPE} 4$ elements and periodic boundary condition. Deformation is strain-controlled by displacing the right edge of nodes (see Fig. 3) with a fullyreversed triangular waveforms and peak strain of 0.015 at a constant strain rate of $5.83 \times 10^{-4} / \mathrm{s}$. The 
constitutive behavior from simulations saturates rapidly and the stress-strain loop after two computational cycles matches the saturated experimental curve. By assuming identical material properties and limiting the slip systems that nucleate cracks, our approach reduces the complexity of the physical model without sacrificing the engineering applicability to predict the crack growth and fatigue life with the aid of statistical calibration and post-processing.

Table 2 Material and crystal plasticity parameters

\begin{tabular}{c|c|cc|c}
\hline Elastic stiffness & Flow & \multicolumn{2}{|c|}{$\begin{array}{c}\text { Isotropic hardening } \\
\text { parameters }\end{array}$} & $\begin{array}{c}\text { Kinematic-hardening } \\
\text { parameters }\end{array}$ \\
\hline$C_{11}=253.1 \mathrm{GPa}$ & $n=13.58$ & $\tau_{\mathrm{s}}=177.1 \mathrm{MPa}$ & $f_{\alpha \beta}=3.3$ & \\
$C_{12}=132.4 \mathrm{GPa}$ & \multirow{2}{*}{$\tau_{0}=10 \mathrm{~s}^{-1}$} & $\tau_{0}=118.1 \mathrm{MPa}$ & $f_{\alpha \beta 1}=2.1$ & $c=855 \mathrm{MPa}$ \\
$C_{44}=75.8 \mathrm{GPa}$ & & $h_{\mathrm{s}}=0.002 \mathrm{MPa}$ & $q=0.3$ & $d=71$ \\
& & $\gamma_{0}=0.0075$ & $q_{1}=0.2$ & \\
\hline
\end{tabular}




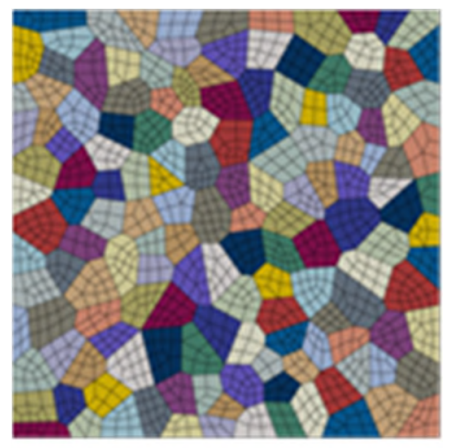

(a)

(b)

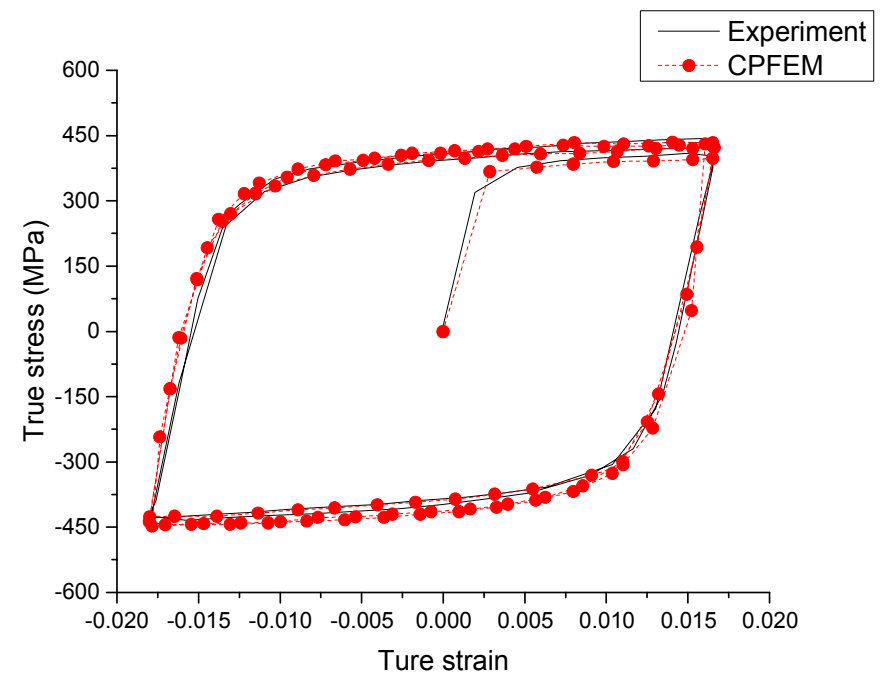

Figure 3. (a) FE mesh for a $400 \mu \mathrm{m} \times 400 \mu \mathrm{m}$ model with 150 grains, 1386 CPE4 elements, and fully periodic boundary condition (b) Stress-strain response from simulations and experiments ([52]). Note that the constitutive behavior from simulations saturates rapidly and the stress-strain loop after two computational cycles matches the saturated experimental curve.

\section{IMPLEMENTATION IN ABAQUS AND EXAMPLE TEST}

\subsection{General procedure for implementation in ABAQUS}

Random realizations of synthetic microstructures are generated for each weld zone. Each grain is entirely subdivided into several SBs parallel to the $\{110\}<111>$ slip systems that correspond to potential PSBs. After applying two computational cycles, cracks initiate at the SB with the largest SB-averaged FIP, and the corresponding nucleation life is obtained from Eq. (3). Next, the elastic stiffness for the elements along the cracked SB is reduced isotropically up to $99.9 \%$, and the cyclic loading process continues to promote stress redistribution. The path for the crack extension is assumed to be transgranular along the SBs and the number of cycles required to fully crack each subsequent grain is evaluated based on the method discussed in Section 2.2. Crack arrest at grain 
boundaries is automatically captured if $d a / d N=0$. The flowchart of the modeling approach is included in the previous work [55], and Fig. 4 presents a schematic representation of the crack growth sequence based on the proposed approach.
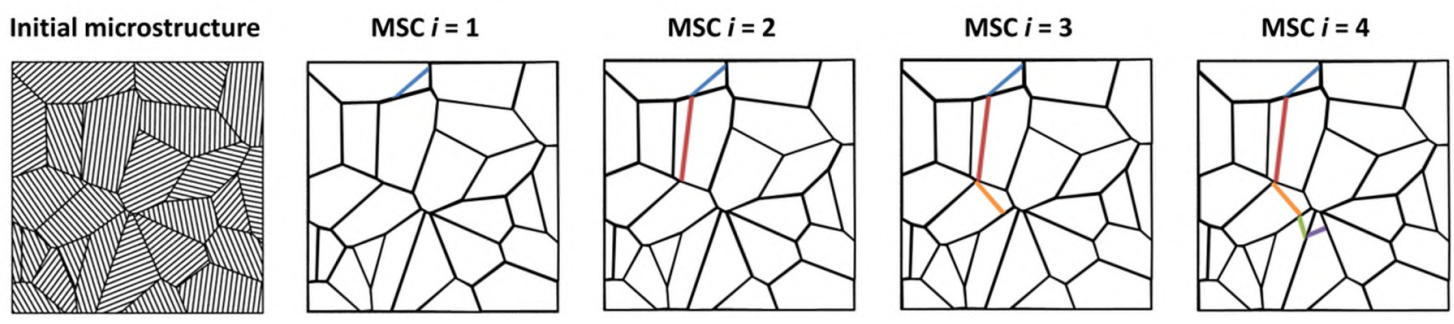

Figure 4. Schematic representation of the nucleation and growth of a fatigue crack along predefined SBs. Black and white lines in the initial microstructure correspond to crystallographic SBs and colored bands correspond to the grain-by-grain crack growth (SBs not shown for clarity upon crack nucleation and growth).

\subsection{Verification of non-local FIP for BCC single crystal}

Prediction of fatigue crack growth resistance of individual grains is based on computing mesoscale FIPs, particularly the Fatemi-Socie parameter averaged over SBs. This fatigue driving force was originally proposed to predict crack initiation in macroscopic experiments in FCC and BCC metallic alloys [40,56]. More recently, a crystallographic version of the Fatemi-Socie FIP was validated at the mesoscale by comparing FIPs with cyclic crack tip displacements $\triangle \mathrm{CTD}$ in OFHC $\mathrm{Cu}$ and RR1000 Ni-base alloy [37,57]. These investigations demonstrated a correlation between FIP and $\triangle \mathrm{CTD}$ under shear and mixed mode loading.

To further support the validity of the crystallographic Fatemi-Socie FIP in BCC metals, this study performs a similar verification applied to BCC BM steel, with a predefined crack plane and extension direction along with $\{110\}<111>$ slip system. Simulations consider a single crystal with 
a blunt crack tip adjacent to a SB as shown in Fig. 5. The $\Delta$ CTD corresponds to the displacement between two nodes in red in the detailed view of the crack tip in Fig. 5. Two computational cycles were applied to different crack lengths and loading directions to investigate the relationship between FIP and $\triangle \mathrm{CTD}$ following the same procedure as in Ref. [57]. The FIP was averaged in this case within a uniform band of $2 \mu \mathrm{m}$ thickness parallel to the crack, shown in gray in Fig. 5 .

Results in Fig. 6 indicate, in logarithmic scale, a linear relation between the $\triangle \mathrm{CTD}$ and the FIP for both loading modes. This relation breaks down for $\Delta$ CTD values below the magnitude of the Burgers vector $\left(\sim 2.5 \times 10^{-4} \mu \mathrm{m}\right)$. A least square analysis in logarithmic scale to fit the power law,

$$
\mathrm{FIP}=A(\Delta \mathrm{CTD})^{b}
$$

results in an exponent $b$ of 0.75 under shear mode and 0.69 under mixed mode while the other fitting parameter $A$ is 1 and 0.72 , correspondingly. Conversely, it means FIP is equivalent to $\triangle \mathrm{CTD}$ with exponent larger than one. Therefore, taking FIP $\sim \Delta$ CTD is still conservative since FIP is mostly small than one. In this case, the verification suggests that non-local FIP can be used as a substitution of local driving force for fatigue in both BCC and FCC metal in a safe manner.
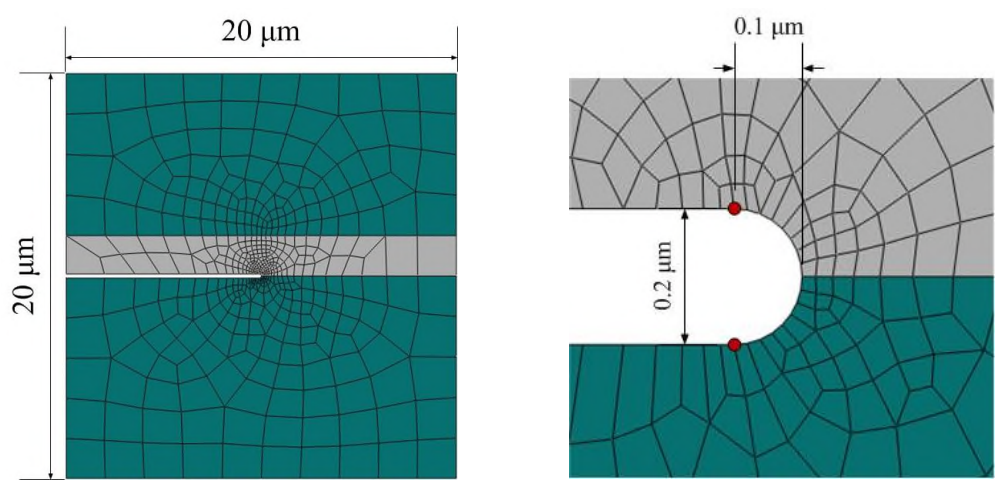

Figure 5. Finite element model with a deep crack in a single crystal. Shear or mixed mode loading is applied to the upper and bottom boundaries (similar model as Fig. 4 in [57]). 

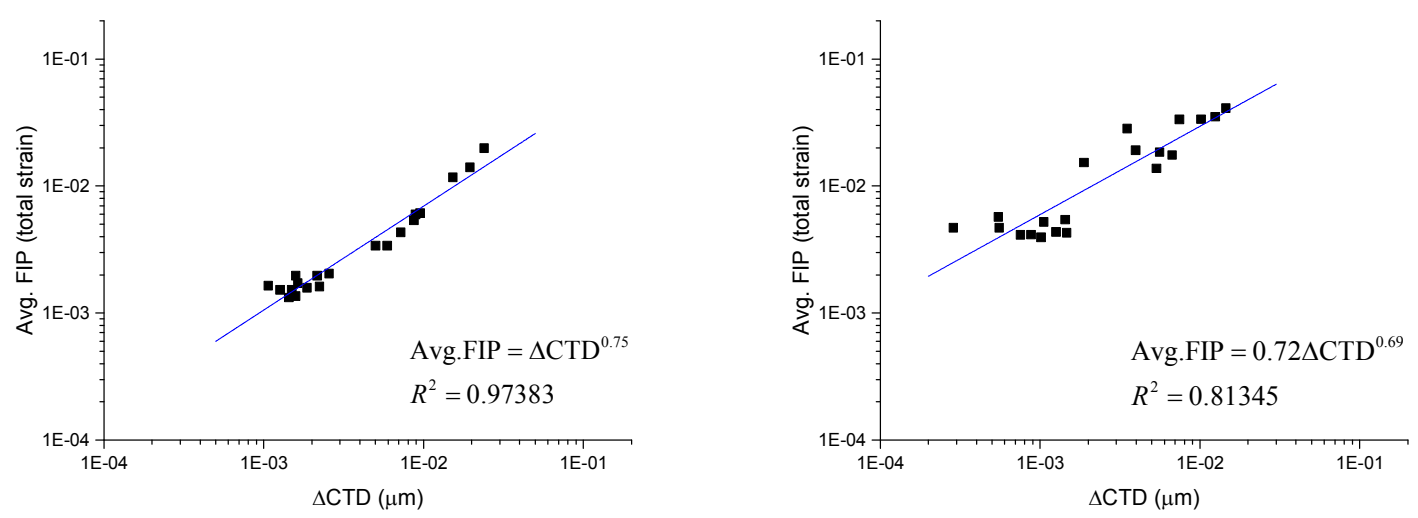

Figure 6. Comparison of computed SB-averaged FIP vs. $\triangle$ CTD for (left) shear and (right) mixed mode loading.

\subsection{Estimation of irreversibility parameters}

In addition to the calibration of the constitutive model, three irreversibility parameters in Eqs. (4) and (6) need to be calibrated to estimate fatigue lives: irreversibility coefficient $\alpha_{\mathrm{g}}$, mechanical irreversibility measurement $\phi$ at the crack tip process zone and cyclic CTD threshold for dislocation emission $\Delta \mathrm{CTD}_{\text {th. }}$. A precise estimation of the parameters would require crack growth data from small crack fatigue experiments or bottom up multiscale simulations, which are extremely scarce, especially for welded material. Due to the unavailability of small crack fatigue data for typical bridge welds, our calibration relies on reference experiments from the literature for comparable materials and environments. In addition, we assume that all the weld regions have identical $\alpha_{\mathrm{g}}, \phi$ and $\Delta \mathrm{CTD}_{\text {th }}$, which follows from the fact that irreversibility is controlled by atomistic rather than mesoscale processes (e.g., dislocation emission, cross slip, adsorption of species, etc). These processes are similar among the weld zones and other metallic materials with similar, environments, composition and phases. For instance, the minimum possible crack growth from a crack tip controls $\Delta \mathrm{CTD}_{\text {th }}$ and it is related to the emission of a dislocation. Thus, the 
magnitude of the $\Delta \mathrm{CTD}_{\text {th }}$ is on the order of the Burgers vector for BCC crystal of iron, $\triangle \mathrm{CTD}_{\text {th }} \approx$ $4 \times 10^{-4} \mu \mathrm{m}$. This magnitude is indeed the same for all weld zones.

The reference experiments [9] were carried out for Al-killed Nb-V microalloyed Grade S550 MC high strength steel that is widely used materials in transportation infrastructure and is comparable to SAE J1392 X80 or API 5L X80 HSLA. The test specimen was ground to $5.2 \mathrm{~mm}$ thick and grooved at the HAZ (4mm radius and $0.5 \mathrm{~mm}$ depth) as shown in Fig. 7(a). The mean grain size of the HAZ is roughly $10 \mu \mathrm{m}$.

To quantify the stress intensification induced by the groove we modeled the specimen in Fig. 7(a) assuming a elastoplastic material response [9]. A BCC model is used since the ferrite-bainite microstructure is present after MAG (metal active gas) welding process. The results in Fig. 7(b) show that stress gradient, $\sigma_{x x}$, is relatively smooth compared to the grain size. Thus, instead of modeling the entire grooved specimen, we consider a $100 \mu \mathrm{m}$ x $100 \mu \mathrm{m}$ crystal plasticity domain in Fig. 7(c) subjected to a loading condition equivalent to that at the root of the groove. Multiple SVE realizations under constant cyclic load equivalent to that at the groove are employed to reproduce the small fatigue crack variability.

The SVE has a top boundary free of constraint, a bottom boundary constrained to move along the $\mathrm{Y}$-axis, and periodic boundaries along the $\mathrm{X}$-axis. The maximum and minimum longitudinal stress at the groove bottom is $610 \mathrm{MPa}$ and $75 \mathrm{MPa}$ based on pre-mentioned macroscopic analysis. Considering the residual stress profile obtained from the same set of referred experiments [9], which has a representative value of $-117 \mathrm{MPa}$ at at the root of the groove, the load on the side edge of the SVE is taken as $493 \mathrm{MPa}$ to $-42 \mathrm{MPa}$ and triangle loading at $10,700 \mathrm{MPa} / \mathrm{sec}$ (according to the fatigue test frequency of $10 \mathrm{~Hz}$ ), which assumes linear elastic addition of stress fields. 
A total of 150 microstructural realizations were simulated to compute FIPs distributions, whose mean values are employed to estimate the irreversibility parameters. In addition, another set of simulations were performed using the calibrated parameters to estimate fatigue life predictions. The distribution of maximum FIPs for the first six cracked grains is shown in Fig. 8. and Fig. 9, which compiles the same information boxplots. At each box, the central mark (Q2) is the median, while the edges of the box are the 25th and 75th percentiles (Q2 and Q3, respectively). The whiskers extend to the most extreme data points with the range Q1-1.5 (Q3-Q1) Q3+1.5 (Q3-Q1) and outliers are plotted individually by mark "+". As shown in Fig. 11, the FIPs for the first grain cracking are significantly higher than those in subsequent crack growth, while the FIPs are comparable among these grains. Moreover, FIP distributions are not symmetric and have a longer tail towards larger values; these extremes indeed dominate fatigue lives. 


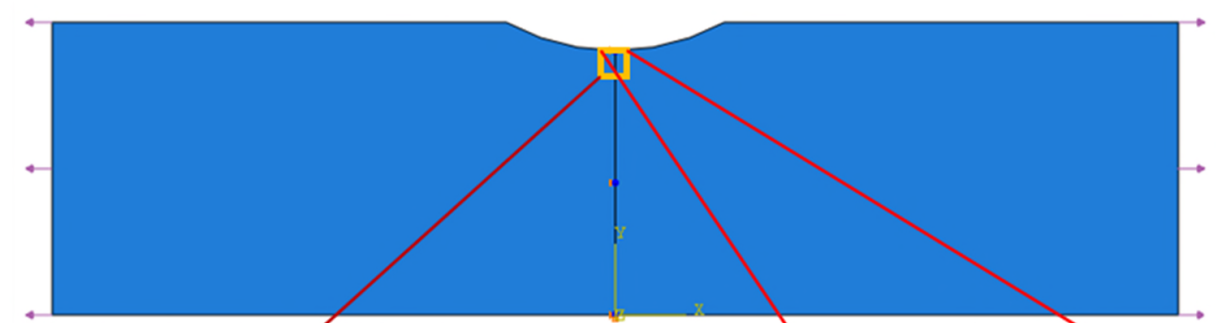

(a) Partial specimen (5.2m/n thick and $20 \mathrm{~mm}$ long) with grooved HAZ (4mm radius and $0.5 \mathrm{~mm}$ depth)

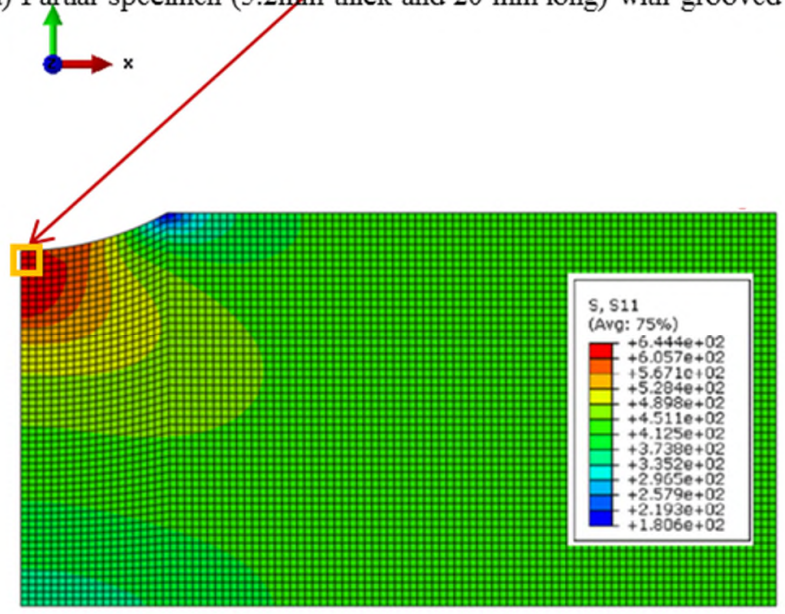

(b) $\sigma_{x x}$ under macroscale elastic-plastic analysis

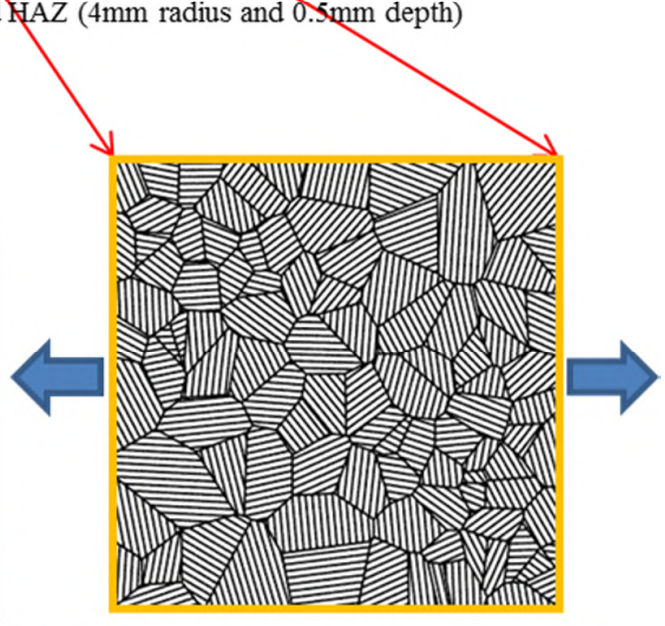

(c) SVE $100 \mu \mathrm{m} \times 100 \mu \mathrm{m} 10 \mu \mathrm{m}$ grain

Figure 7. Grooved specimen and meshes used for calibration of irreversibility parameters.

An elastic model estimated the applied load in a subdomain at the bottom of the groove, which corresponds to the SVE analyzed with the crystal plasticity and fatigue models.
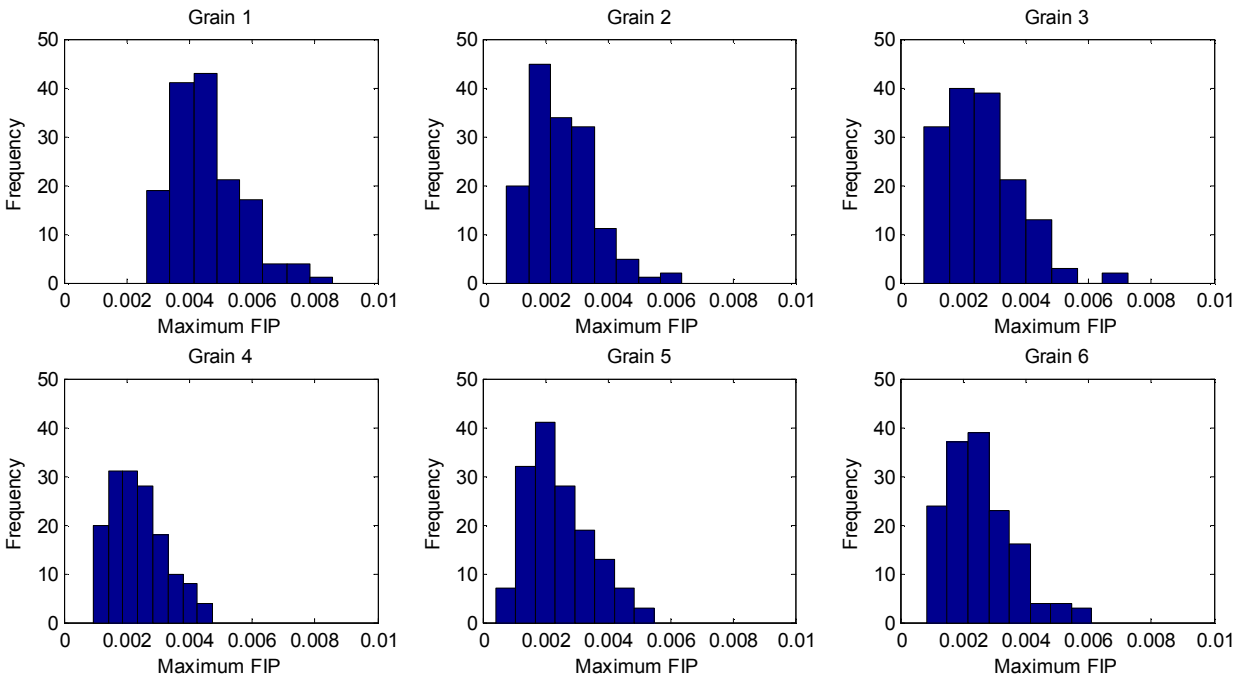
Figure 8. Distribution of maximum FIPs for the first six grains that failed from among all 150 simulations.

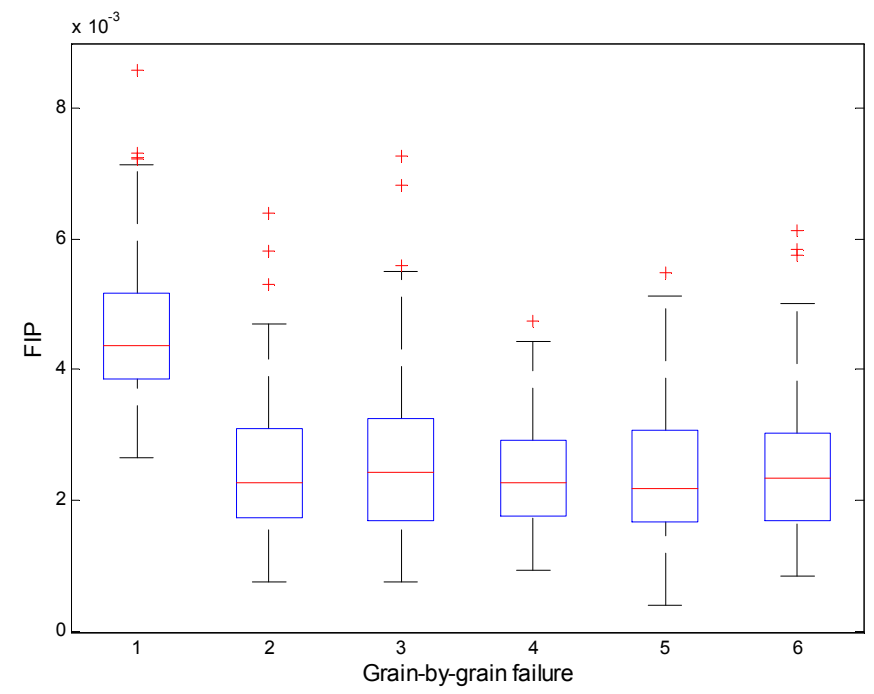

Figure 9. Boxplot by compiling the FIP distributions from Fig. 8 for the first six grain fractured on a grain-by-grain basis.

Parameter $\alpha_{\mathrm{g}}$ for the nucleation regime is determined by assuming a value for each unknown in Eq. (3). Thus,

$$
\alpha_{g}=N_{n u c} d_{g r}\left(\operatorname{FIP}_{\text {meso }}^{(\alpha)}\right)^{2}=47.1 \text { cycles } \mu \mathrm{m}
$$

by assuming that,

- $N_{n u c}=70,000$ [9], which corresponds to the fatigue life consumed when the dominant crack reaches one mean size grain in length.

- $D_{s t}=10 \mu \mathrm{m}$; taken as mean grain size [9].

- $\omega=0$; since most misorientation exceeds $20^{\circ}$, as estimated from the random grain generations. 
- $\quad \mathrm{FIP}_{\text {meso }}^{(\alpha)}=0.0092$, which is the extreme value obtained in Fig. 9.

The calibration of $\phi$ in Eq. (5) for the MSC growth regime is based on the crack growth rate data from [9], reproduced and shown in Fig. 10. The curve starts with an initial decreasing crack growth rate which is assumed to correspond to the nucleation regime. From the fluctuating small crack growth rate due to GB crossing, the minimum crack growth rate is estimated as $5 \times 10^{-6}$ $\mu \mathrm{m} /$ cycle, and the average maximum rate when a grain begins to crack is taken as about $8 \times 10^{-4}$ $\mu \mathrm{m} /$ cycle.

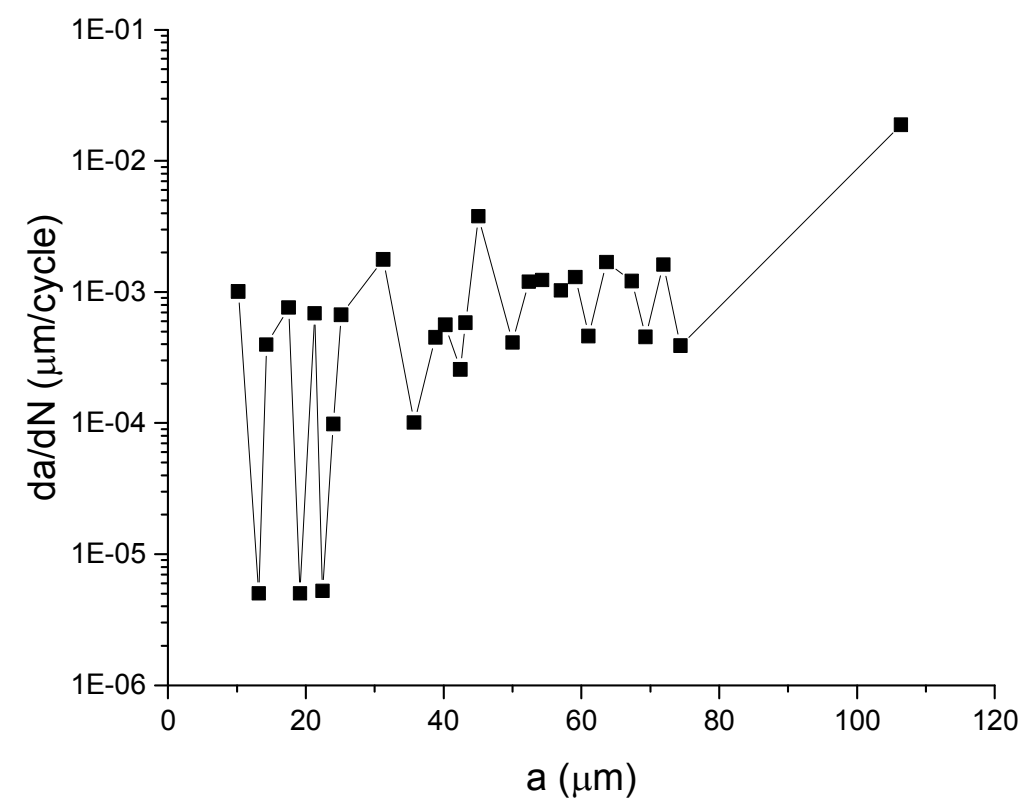

Figure 10. MSC growth rate data of HAZ (reproduced from Figure 14 in [9]).

The calibration of constant $\phi$ assumes that

- $\left.\frac{d a}{d N}\right|_{m s c} ^{(\alpha)}=8 \times 10^{-4} \frac{\mu \mathrm{m}}{\text { cycle }}$, which is roughly the average crack growth rate after crack cross the GB. 
- $D_{s t}=10 \mu \mathrm{m}$ and $\omega=0$; following the same arguments considered for the calibration of $\alpha \mathrm{g}$.

- $\operatorname{FIP}_{\text {meso }}^{(\alpha)}=0.0065$, which is the average remaining FIP after the reduction on the FIP of nucleation regime in Fig. 9.

Therefore, the transgranular irreversibility factor becomes $\phi=0.063$ which is within the custom range of $0.01 \sim 0.1[33]$.

\subsection{MSC simulation and statistics of results}

This section assess the early fatigue lives for different weld regions, which are all assumed to be located at a macroscopic stress raiser (worse case scenarios) and cracks nucleate on surface grains (prescribed for only one crack nucleation and subsequent growth). Sixty microstructural realizations are carried out assuming that the top surface is free of constraint, a bottom surface constrained to move along the $\mathrm{Y}$-axis, and periodic boundaries along the $\mathrm{X}$-axis. A triangular cyclic strain is applied along the $\mathrm{X}$-axis, with peak strain $0.5 \%$, at a rate of $0.5 \% / \mathrm{sec}$, and strain rate $R_{\varepsilon}=0$.

An example of the grain-by-grain crack growth sequence is presented in Fig. 11 for microstructure. The figure presents a sequence of strain localization, crack nucleation, stress redistribution, and crack propagation and arrest. In some cases, the SB with the highest FIP plastic strain may occur below the surface grain in the nucleation regime. However, the assumption that the first crack starts at surface grain is still appropriate due to the influence of the environment on the irreversibility parameters, which were calibrated for an active atmosphere, not vacuum. Indeed, subsurface crack initiation only becomes more likely in the very high and ultra-high cycle fatigue regimes, in which the marked heterogeneity in plastic deformation competes with the irreversibility of the environment. 

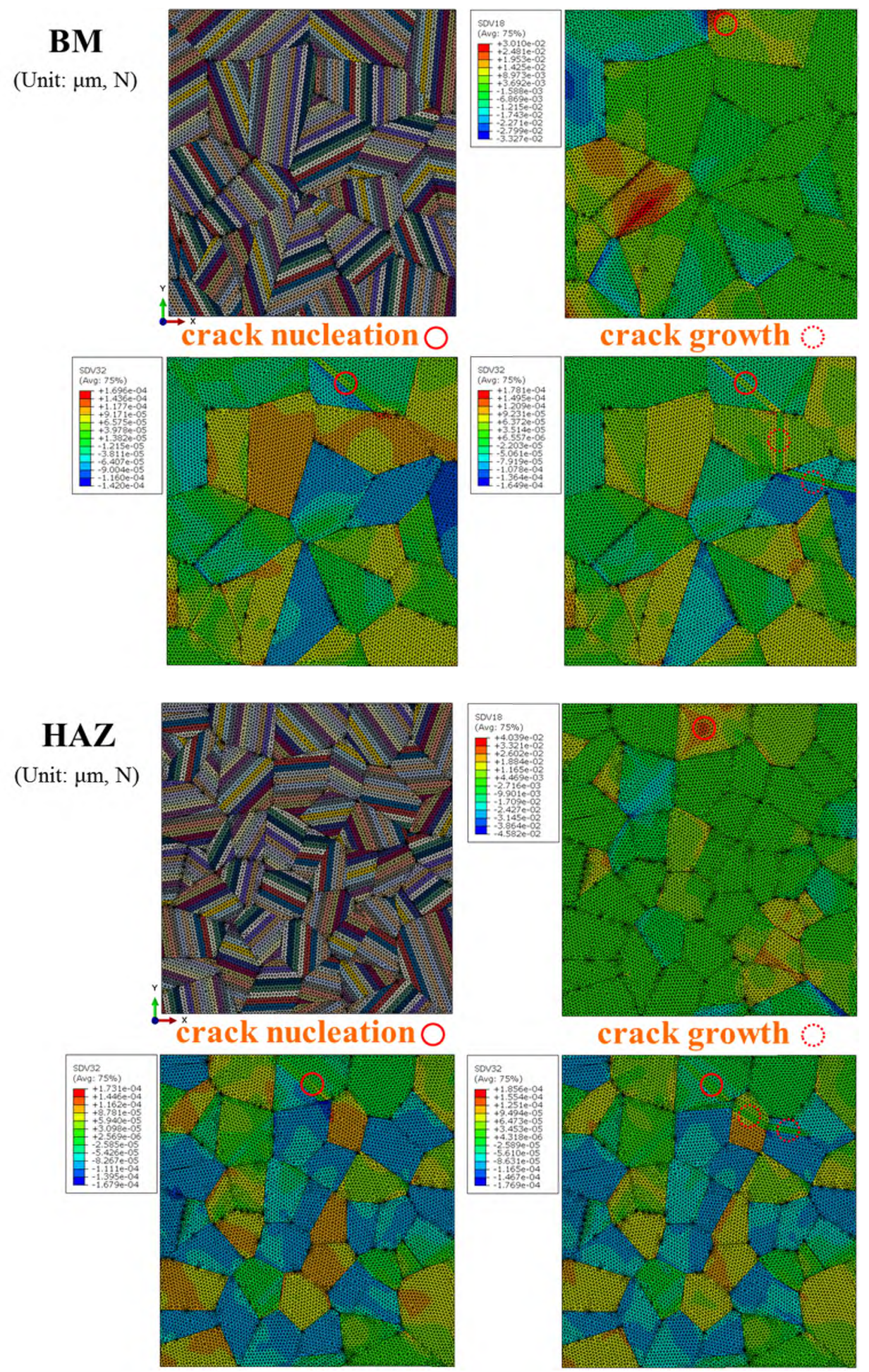


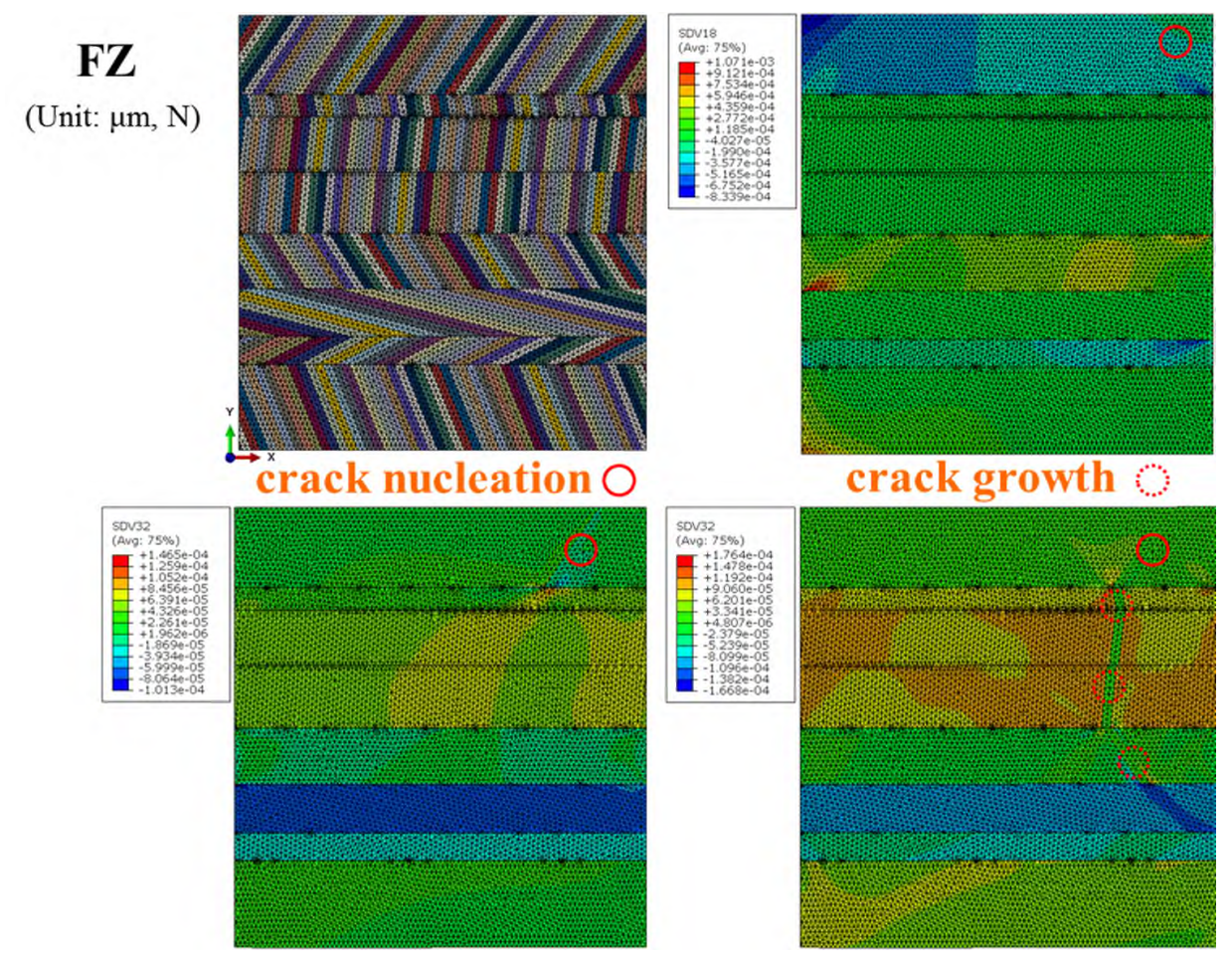

Figure 11. Crack growth, strain and stress in weld zones for one simulation

(upper left - SB distribution, upper right - plastic shear strain (SDV18) after two load cycles, lower left -resolved shear stress (SDV32) at two cycles after nucleation, lower right - MSC path at the end)

The Y-axis projected crack length $a$ vs. $N$ diagrams for three weld zones are plotted in Fig. 12. Each data point represents extending the crack by one grain until arrested or reach the SVE boundary. Furthermore, each line that connects dots represents one simulation and the slope indicates the crack growth rate. The crack growth rates oscillate (as expected for MSC), but the trend is increasing until encountering a strong barrier. Seldom can the crack grow through the entire SVE, but a direct comparison with experiments of the crack arrest probability should consider 3D models. As shown in the Fig. 12, the span of nucleation lives are is shorter for BM than for HAZ and FZ, which suggests that grain morphology has a detrimental effect crack 
nucleation. In comparison, crack growth in BM seems to present wider spread compared to the FZ and HAZ. Meanwhile, the cracks in FZ are arrested more often than those in BM and HAZ as shown in the figure.
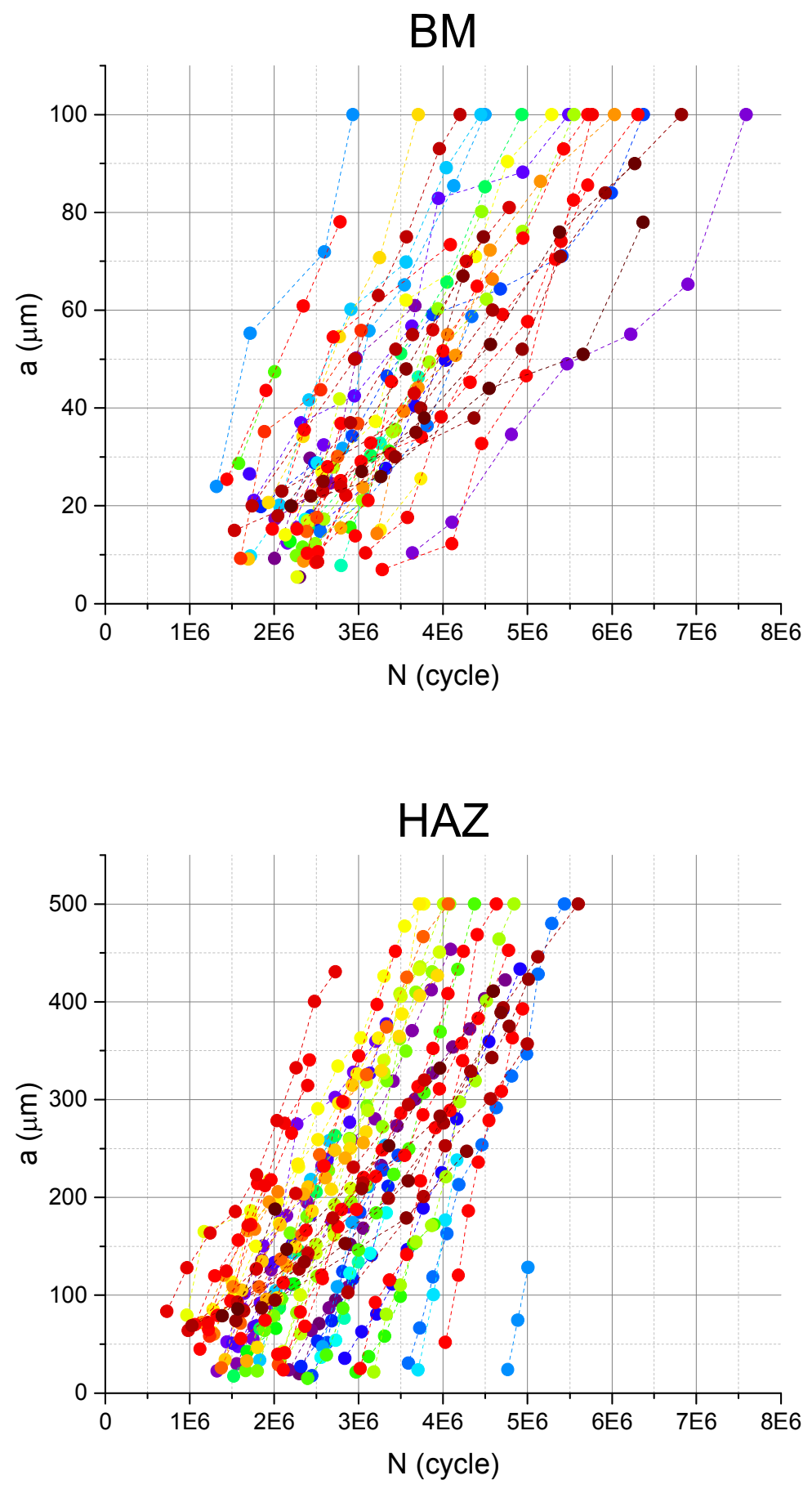


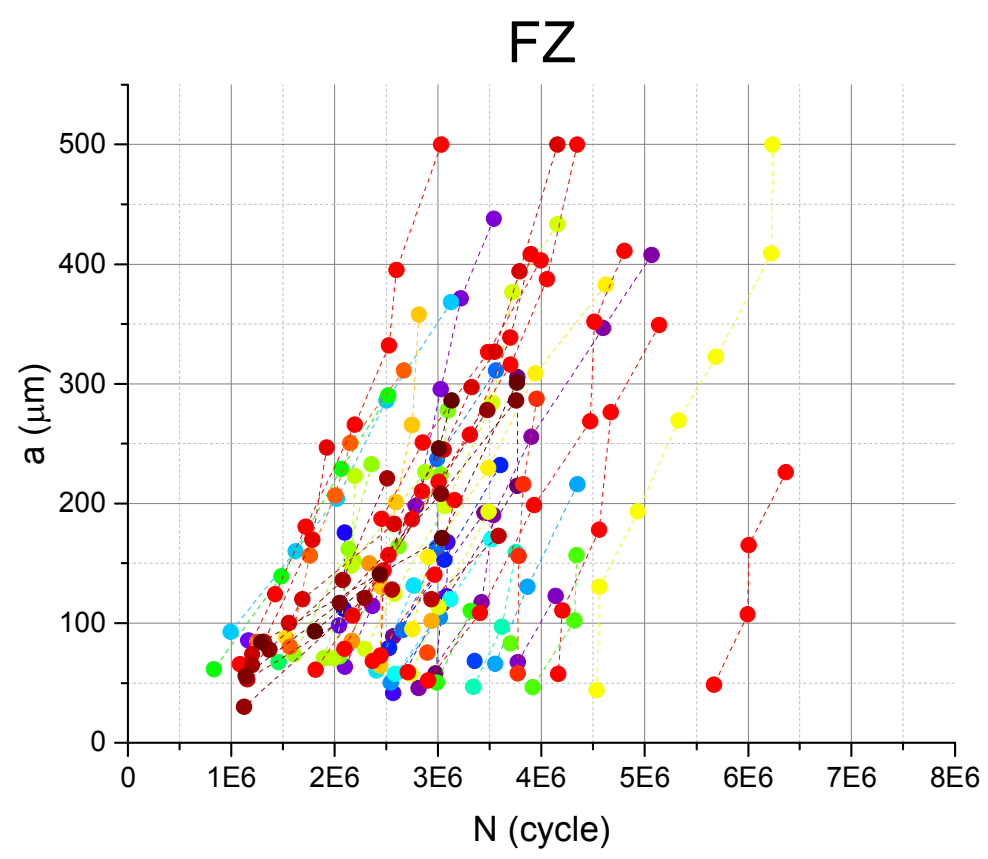

Figure 12. Crack length (projected) vs. number of load cycles for three weld zones.

Table 3 presents some significant statistics: Min $N_{n u c}$ and $\operatorname{Max} N_{n u c}$, represent the maximum and minimum crack nucleation life in the surface grain in all simulations for each zone, respectively, the $5 \%$ nucleation probability corresponds to the third shortest nucleation life computed, and the average cycle numbers to form a $100 \mu \mathrm{m}$ crack.

The results show that the number of cycles for BM to develop a $100 \mu \mathrm{m}$ crack can double those for HAZ and FZ, while the FZ has the smallest value. These differences result from different grain size and morphology between the HAZ and the FZ.

Table 3 Most significant statistics for MSC nucleation and growth in welds.

\begin{tabular}{c|c|c|c}
\hline & BM & HAZ & FZ \\
\hline Min $N_{\text {nuc }}$ & $1,316,966$ & 728,618 & 832,034 \\
\hline
\end{tabular}




\begin{tabular}{c|c|c|c}
\hline Max $N_{\text {нuс }}$ & $3,637,766$ & $4,765,911$ & $5,669,326$ \\
\hline $5 \%$ prob. $N_{\text {nuс }}$ & $1,529,173$ & 982,348 & $1,084,039$ \\
\hline Avg. $N$ for 100 & $5,353,025$ & $2,258,445$ & $2,599,180$ \\
$\mu \mathrm{m}$ crack & & & \\
\hline
\end{tabular}

To compare the effects of the microstructure on crack growth, Fig. 13(a) presents the crack length normalized by the SVE size. As shown in the figure, at the crack nucleation stage (first grain crack), the distributions for the crack nucleation (first grain crack) are similar for the three zones. However, as more grains are cracked, the slope of the curves, which is the ratio of the normalized crack to the cracked grain numbers, shows more variability. In comparison, BM has a higher ratio than those for HAZ and FZ, which suggests that the SVE in BM gets fully cracked with less number of grains. Such differences are due to the grain size, SVE size (characteristic transition length to PSC or LC), and the grain shape (lath-like grain shape in FZ ends up with much less grain to be fully cracked). Fig. 13(b) shows the crack growth rate (CGR) for the three zones. It is noteworthy that the vertical axis is in a logarithmic scale. As shown in the figures, CGR increases after nucleation. In the three zones, BM has the smallest value of CGR compared with those for FZ and HAZ. Compared with those for BM and HAZ, FZ has the largest variations of CGR. Additionally, a large overlap of CGR values for FZ and HAZ can be found, as well. 


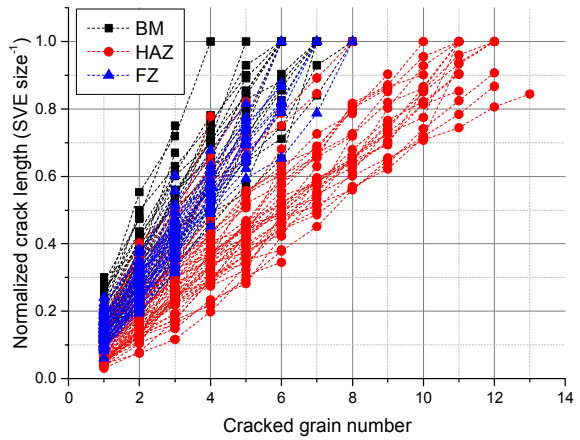

(a)

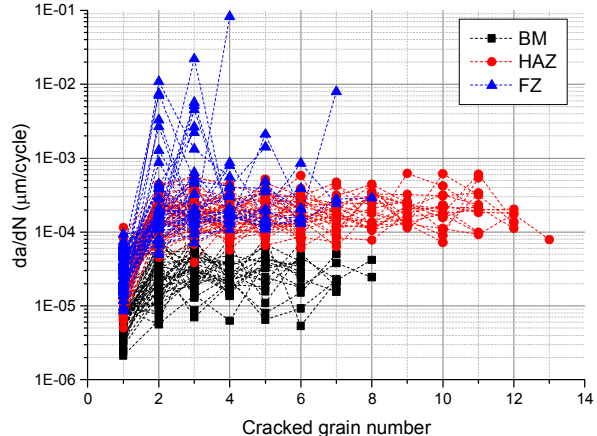

(b)

Figure 13. Crack growth variation with cracked grain number in three weld zones. Each connected dot series is from one simulation. (a) is the SVE size-normalized crack length growth; (b) is the variation of the crack growth rate along the crack path.

To compare the scattering, Fig. 14 presents the coefficient of variations (COVs) of the number of cycles $\Delta N$ to crack a grain, the crack extension $\Delta a$, and CGR $d a / d N$ for each cracked grain. Most COVs fall in to the range between 0.1 and 1 , and it has a general slightly decreasing trend but increasing fluctuation with increasing grains cracked. Among three weld zones, BM shares similar trends with HAZ but the FZ has a larger discrepancy. We argue that the morphology rather than the size of the grain are responsible for such differences. 


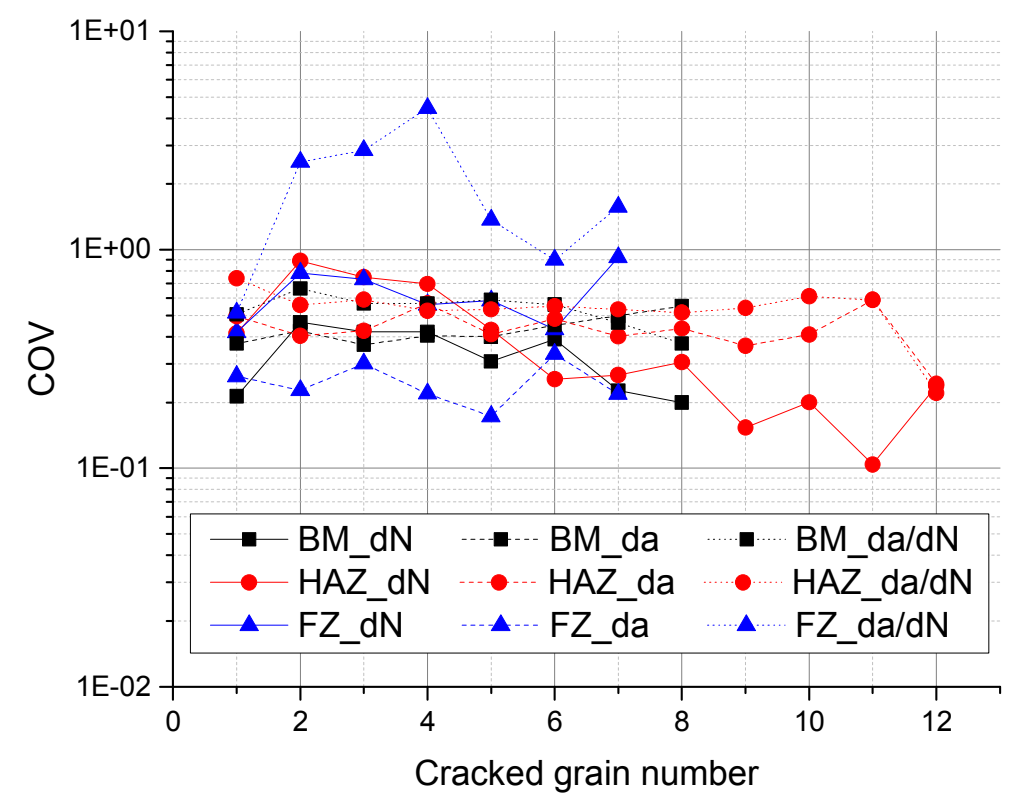

Figure 14. COVs of $\Delta N, \Delta a$, and $d a / d N$ in three weld zones.

For a further study of CGR with relation to the macro-scale measure, CGR is plotted versus crack length in Fig. 15. To eliminate the size effect, the SVE size-normalized crack length is used. The shape of the line is stepped since the CGR is considered to be constant in subgrain growth (refer to Section 2.2). After the normalization, a major part of the curves from three weld zones are overlaid. Most of the HAZ curves overlap, while the curves for FZ show largest variability. These discrepancies mainly come from the grain shape and deviation of the grain size. 


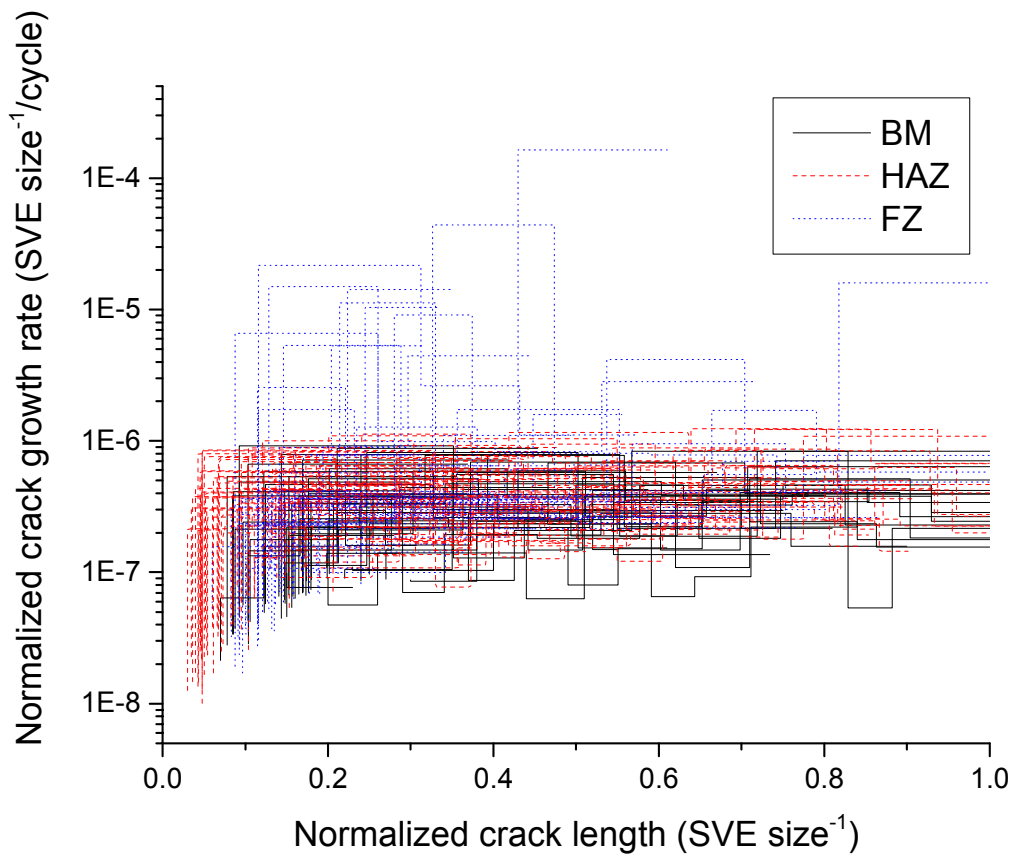

Figure 15. Crack growth rate vs. normalized crack length in three weld zones.

Finally these simulations provide the means to compute probabilistic MSC growth curves in Fig. 16 where linear interpolation is applied to get the cycle number for a specific crack length. A special normalized standard deviation (NSTD) is used to integrate the comparison of the fatigue life variability in one weld zone and across three weld zones, namely, the standard deviation of cycle number consumed by a specific crack length are normalized by cycle number value averaged from all data points of each weld zone (refer to Fig. 12). As shown in Fig. 16, the range of mean value of fatigue life $N$ (cycle number consumed) is between $1.5 \times 10^{6}$ and $5.5 \times 10^{6}$, and the range of NSTD is between 0.2 and 0.5 . Overall, the mean $N$ increases almost linearly for all zones. NSTD shows a different trend for each zone — slightly increasing for BM, slightly decreasing for HAZ, and slightly decreasing and then increasing for HAZ. In the very early phase of fatigue (mainly nucleation regime), mean value and NSTD of $N$ for BM is slightly smaller than that for HAZ and FZ. During the MSC propagation regime, the mean value of $N$ for BM increases faster and exceeds 
that for HAZ and FZ, while its NSTD of $N$ slightly increases and exceeds that for HAZ. These phenomena are related to the grain size to SVE size ratio or the number of grains. For the mean value of $N$, the lower number of grains in $\mathrm{BM}$ reduces the chance to have severe strain concentration, leading to longer fatigue life. For NSTDs, to crack the first surface grain, the HAZ has a larger NSTD because of more grains on the surface compared with BM. Then the NSTD drops to a plateau since more grains in the subsequent cracking steps mean more chances to develop the same crack length until stabilization. However, as for BM, with fewer further cracking paths (through potential grain sequence ahead) but large variability of grain size, an increasing NSTD is expected. Compared with BM/HAZ, the thickness variation of lath-like grain in FZ also introduced larger variations for FZ.

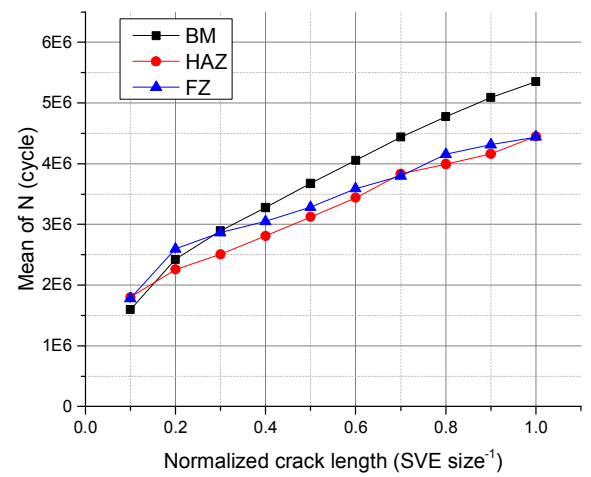

(a)

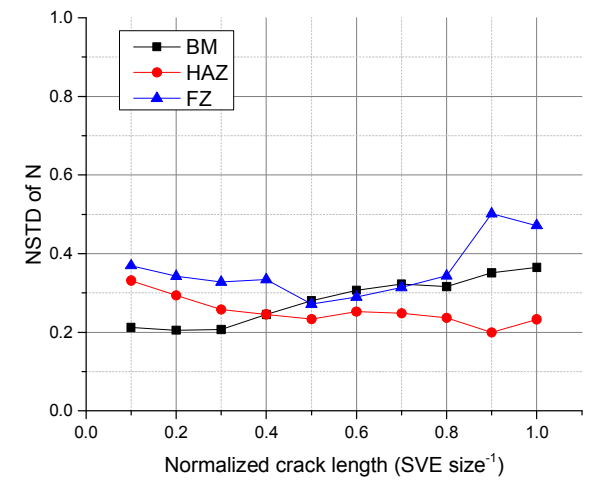

(b)

Figure 16. Mean value (a) and variability (b) of the fatigue life vs. crack length.

\section{DISCUSSION}

- Simplification of 2D models

The representation and solution of the MSC problem in $2 \mathrm{D}$ is a significant simplification, but it does not prevent us from assessing a few key effects of the microstructure on fatigue cracks. Certainly, we do not aim for precisely modelling 
crack growth to qualify the life of a component but to compare the relative detrimental effects on fatigue of the various weld zones in joints. A 2D model is a balanced effort that can incorporate complex microstructure information and request statistical realizations to compute low probability fatigue cracking event. Having proved the usefulness of the framework, future work will implement the approach in this paper to study welds with 3D models.

- Constitutive model

The quality of the constitutive model affects the quantification of the fatigue driving force and introduces some uncertainty. The crystal plasticity model is a continuum description of the crystal behavior that partitions the strain among the slip planes based on the phenomenological description of dislocation glide. Here, the crystal plasticity model has parameters calibrated to reproduce the cyclic stress-strain curve, but these parameters may not be unique. Lack of uniqueness does not preclude the use of these parameters to estimations of the final damage. Although the model has not been validated for a specific crystal orientation, there is much higher confidence that the response of an ensemble of grains can be predicted. This explain why we do not focus on the local grain environment that initiate/propagate a crack, but on the trends from the ensemble. Future work should aim for a formulation informed by physical bottomup approaches (such as first principle calculation by atomic mechanics).

- Fatemi-Socie model and $k$ parameter

The Fatemi-Socie parameter [40] is widely applied for critical plane approach and depends on a material constant $k$, which can be found by fitting fatigue data from simple uniaxial tests to fatigue data from simple torsion tests. Generally, $k=1$ is suggested as 
a first approximation if test data not available [41]. However, $k$ may differ from 1 or not be constant for the different number of cycles, i.e., different $k$ for different material and different $k$ under different crack length criteria for defining failure of one material. The range of $k$ can be from $0 \sim 2$ for a variety of steel using different failure definition based on Park and Nelson's research [58]. For steels similar to that considered on the paper - Ck45, 30CrMiMo 8, 42CrMo4, X $10 \mathrm{CrNiTi} 18$ 9, and 1\% CrMoV $-k$ has been found to be $0.4,1.0,1.0,1.4,1.2$ under small crack length criterion $[58,59]$. Therefore, for bridge steel weld, $k=1.0$ is taken as a good approximation for the Fatemi-Socie damage parameter.

In the integration with crystal plasticity for crystallographic cracks, Castelluccio [57] has shown that $k$ only plays a significant role when considering multiaxial loading. Hence, within a single grain equally good damage predictions (based on crack tip displacements) can be obtained with various $k$ as long as the same loading is applied (e.g., tensile or shear), but an optimal $k$ (close to $k=1$ ) arises for using a single parameter for multiple loading directions (which was indeed the original intend from Fatemi and Socie). Furthermore, the paper considers a single nominal loading direction, although grains will naturally have a local multiaxial component. Further understanding of the physical meaning of Fatemi-Socie parameter would be beneficial, but it is beyond the scope of the present paper. Furthermore, different $k$ will impact the FIP and mean fatigue life, but less likely the spread and ranking of microstructures.

- Fatigue model formation, calibration and validation

The microstructure-sensitive fatigue model (Eqs. (2-6)) is based on FIPs and irreversibility parameters. Like Paris' law, the model form needs to be tested by many 
practices and experiences to be accepted. Regarding the irreversibility coefficients, the situation is similar to the constitutive model in the sense that crack growth trends would hold even if these parameters are modified. The quantitative interpretation of the atomistic process in crack tip zone would help to quantify these parameters with an additional validation from small crack growth tests. For the current paper, due to the limited experimental data, especially for crack growth for infrastructural material like bridge steel, a better calibration and validation for our current model is not able to be performed. Therefore, the experimental work is scheduled for the authors now. Due to the large uncertainties, experiments need to repeat for multiple times for a cluster of crack length vs. cycle number (time) curves to compare with the one from proposed model. There is a clear trend that the calibration and validation need to shift to probability based.

- RVEvs. SVE

Traditionally, the size of RVE are validated based on the stress-strain response and they are constructed as a deterministic representation of a material using the microstructure data from experiments or simulations. However, fatigue crack growth problem is dominated by extreme rather than mean values, which implies that the RVE for FIP prediction needs to be much larger than that to reproduce the stress-strain curve. Such a large RVE carries an unfeasible computational cost. Instead, we opt to model SVEs and multiple realizations, which provide a scalable and efficient estimation of crack growth and fatigue life in a stochastic sense. The optimal SVE size and number of 
realizations that yield accurate prediction for each weld zone should be analyzed in future work.

\section{CONCLUSION}

This paper employs a small crack simulation framework built on microstructure-sensitive model and crystal plasticity to predict the early fatigue lives of weld zones with different microstructures. Firstly, a non-local FIP is verified to be suitable for mesoscale driving force in BCC structures. Considering the uncertainty of the microstructure, a probabilistic approach is proposed to calibrate the model for which limited experimental data is available. Simulations study the growth of small microstructure cracks under constant cyclic load by modeling a grain-by-grain crack path.

The results show larger deviations of $a-N$ data for BM than those for HAZ and FZ in MSC regime. Furthermore, the crack growth rate in the FZ has largest variability among the three zones, while the HAZ has the lowest. Future work will focus on performing a full characterization of crack growth rate distributions to quantify the characteristic transition length between small and long cracks. In addition, the whole framework can be easily extended to include weld residual stress inside microstructure and environmental effects, and can serve as a part of multi-scale fatigue prognosis system if variable amplitude loads can be covered. However, there are some limitations such as simplified nucleation, SB based mechanism, and 2D microstructure, etc. Despite these, the proposed framework can still serve as a promising local approach for early fatigue assessment of high-quality weldment. As future work for peers, the full validation of the model requires extensive statistical technique and physical test data throughout the weld microstructure in specific structural components like U-rib joints of an orthotropic deck. 


\section{ACKNOWLEDGMENTS}

This material is based on work supported by the National Science Foundation (NSF Grant CMMI-1537121) and Research Excellence Program (REP) from the Office of the Vice President for Research (OVPR) of the University of Connecticut. These supports are greatly appreciated. Any opinions, findings, and conclusions or recommendations expressed in this material are those of the authors and do not necessarily reflect the views of the sponsors.

\section{REFERENCES}

[1] Wolchuk R. Design manual for orthotropic steel plate deck bridges. AISC, Chicago, Illinois 1963.

[2] Troitsky M. Orthotropic bridges-theory and design 1987.

[3] Zhang W, Cai CS, Pan F. Finite element modeling of bridges with equivalent orthotropic material method for multi-scale dynamic loads. Eng Struct 2013;54:82-93. doi:10.1016/j.engstruct.2013.03.047.

[4] Ya S, Yamada K, Ishikawa T. Fatigue evaluation of rib-to-deck welded joints of orthotropic steel bridge deck. J Bridg Eng 2010;16:49-499.

[5] Radaj D, Sonsino CM, Fricke W. Recent developments in local concepts of fatigue assessment of welded joints. Int $\mathbf{J}$ Fatigue 2009;31:2-11. doi:10.1016/j.ijfatigue.2008.05.019.

[6] Radaj D, Sonsino C, Fricke W. Fatigue assessment of welded joints by local approaches. 2006.

[7] Fricke W. Recent developments and future challenges in fatigue strength assessment of welded joints. Proc Inst Mech Eng Part C J Mech Eng Sci 2014;229:1224-39. doi:10.1177/0954406214550015.

[8] Skorupa M, Skorupa A. Significance of Crack Initiation Period in Structural Steel Welds. Proc. Int. Conf. offshore Mech. Arct. enginneering, ASME, 1993.

[9] Buirette C, Degallaix G. Microstructural effects on short fatigue crack initiation and propagation in high strength steel butt welded joints. Weld World 1998;41:37-48.

[10] Venkateswaran P, Ganesh Sundara Raman S, Pathak SD. Short fatigue crack growth behaviour of a ferritic steel weld metal. Sci Technol Weld Join 2005;10:95-102. doi:10.1179/174329305X29500.

[11] Ghosh P, Babu P, Gupta P. Microstructure-fatigue crack growth rate correlation in multipass submerged arc C-Mn steel weld deposit. Int J Fatigue 1995;5:376.

[12] Zheng X, Baotong L, Tianxie C. Fatigue tests and life prediction of $16 \mathrm{Mn}$ steel butt welds without crack-like defect. Int J Fract 1994;68:275-85.

[13] Lautrou N, Thevenet D, Cognard J-Y. Fatigue crack initiation life estimation in a steel welded joint by the use of a two-scale damage model. Fatigue Fract Eng Mater Struct 2009;32:403-17. doi:10.1111/j.1460-2695.2009.01344.x. 
[14] Remes H, Varsta P, Romanoff J. Continuum approach to fatigue crack initiation and propagation in welded steel joints. Int $J$ Fatigue 2012;40:16-26. doi:10.1016/j.ijfatigue.2012.01.007.

[15] Tanaka K, Mura T. A dislocation model for fatigue crack initiation. J Appl Mech 1981;48:97-103.

[16] Navarro A, de los Rios ER. A model for short fatigue crack propagation with an interpretation of the short-long crack transition. Fatigue Fract Eng Mater Struct 1987;10:169-86.

[17] Krupp U, Düber O, Christ H-J, Künkler B, Köster P, Fritzen C-P. Propagation mechanisms of microstructurally short cracks-Factors governing the transition from short- to longcrack behavior. Mater Sci Eng A 2007;462:174-7. doi:10.1016/j.msea.2006.03.159.

[18] Smith NJ, McGrath JT, Gianetto JA, Orr RF. Microstructure/mechanical property relationships of submerged arc welds in HSLA 80 steel. Weld J 1989;68:11.

[19] Castelluccio GM, Yawny AA, Perez Ipiña JE, Ernst HA. In situ evaluation of tensile properties of heat-affected zones from welded steel pipes. Strain 2012;48:68-74. doi:10.1111/j.1475-1305.2010.00799.x.

[20] Castelluccio GM, Perez Ipiña JE, Yawny AA, Ernst HA. Fracture testing of the heat affected zone from welded steel pipes using an in situ stage. Eng Fract Mech 2013;98:52-63. doi:10.1016/j.engfracmech.2012.11.010.

[21] Miller KJ. The behaviour of short fatigue cracks and their initiation. Part I - A riview of two recent books. Fatigue Fract Eng Mater Struct 1987;10:75-91.

[22] Navarro A, Rios EDL. Short and long fatigue crack growth: a unified model. Philos Mag A 1988.

[23] Pineau A, McDowell DL, Busso EP, Antolovich SD. Failure of metals II: Fatigue. Acta Mater 2015. doi:10.1016/j.actamat.2015.05.050.

[24] Manonukul a., Dunne FPE. High- and low-cycle fatigue crack initiation using polycrystal plasticity. Proc R Soc A Math Phys Eng Sci 2004;460:1881-903. doi:10.1098/rspa.2003.1258.

[25] Sweeney CA, Vorster W, Leen SB, Sakurada E, McHugh PE, Dunne FPE. The role of elastic anisotropy, length scale and crystallographic slip in fatigue crack nucleation. J Mech Phys Solids 2013;61:1224-40. doi:10.1016/j.jmps.2013.01.001.

[26] Kartal M, Cuddihy M, Dunne F. Effects of crystallographic orientation and grain morphology on crack tip stress state and plasticity. Int J Fatigue 2014;61:46-58.

[27] Sangid MD. The physics of fatigue crack initiation. Int J Fatigue 2013;57:58-72. doi:10.1016/j.ijfatigue.2012.10.009.

[28] Sangid MMD, Maier HJH, Sehitoglu H. A physically based fatigue model for prediction of crack initiation from persistent slip bands in polycrystals. Acta Mater 2011;59:328-41. doi:10.1016/j.actamat.2010.09.036.

[29] SINHA S, GHOSH S. Modeling cyclic ratcheting based fatigue life of HSLA steels using crystal plasticity FEM simulations and experiments. Int J Fatigue 2006;28:1690-704. doi:10.1016/j.ijfatigue.2006.01.008.

[30] Ghosh S, Chakraborty P. Microstructure and load sensitive fatigue crack nucleation in Ti6242 using accelerated crystal plasticity FEM simulations. Int J Fatigue 2013;48:231-46. doi:10.1016/j.ijfatigue.2012.10.022.

[31] Dunne FPE. Fatigue crack nucleation: Mechanistic modelling across the length scales. Curr Opin Solid State Mater Sci 2014;18:170-9. doi:10.1016/j.cossms.2014.02.005. 
[32] ABAQUS. ABAQUS Documentation. 6.11. Providence, RI, USA: Dassault Systèmes; 2011.

[33] Castelluccio GM, McDowell DL. Mesoscale modeling of microstructurally small fatigue cracks in metallic polycrystals. Mater Sci Eng A 2014;598:34-55. doi:10.1016/j.msea.2014.01.015.

[34] Krupp U. Fatigue crack propagation in metals and alloys: microstructural aspects and modelling concepts. Jonhn Wiley \& Sons; 2007.

[35] Azar AS, Svensson L-E, Nyhus B. Effect of crystal orientation and texture on fatigue crack evolution in high strength steel welds. Int $J$ Fatigue 2015;77:95-104. doi:10.1016/j.ijfatigue.2015.03.008.

[36] Castelluccio GM, McDowell DL. A mesoscale approach for growth of 3D microstructurally small fatigue cracks in polycrystals. Int $J$ Damage Mech 2013;23:791-818. doi:10.1177/1056789513513916.

[37] Przybyla CP, Musinski WD, Castelluccio GM, McDowell DL. Microstructure-sensitive HCF and VHCF simulations. Int J Fatigue 2013;57:9-27. doi:10.1016/j.ijfatigue.2012.09.014.

[38] Castelluccio GM, McDowell DL. Microstructure-sensitive small fatigue crack growth assessment: Effect of strain ratio, multiaxial strain state, and geometric discontinuities. Int J Fatigue 2015;82:521-9. doi:10.1016/j.ijfatigue.2015.09.007.

[39] Fan JL, Guo XL, Wu CW, Zhao YG. Research on fatigue behavior evaluation and fatigue fracture mechanisms of cruciform welded joints. Mater Sci Eng A 2011;528:8417-27. doi:10.1016/j.msea.2011.08.037.

[40] Fatemi a, Socie DF. Critical Plane Approach To Multiaxial Fatigue Damage Including Outof-Phase Loading. Fatigue Fract Eng Mater Struct 1988;11:149-65. doi:10.1111/j.14602695.1988.tb01169.x.

[41] Stephens RI, Fatemi A, Stephens RR, Fuchs HO. Metal fatigue in engineering. 2nd ed. New York: John Wiley \& Sons; 2001.

[42] Musinski WD, McDowell DL. Simulating the effect of grain boundaries on microstructurally small fatigue crack growth from a focused ion beam notch through a threedimensional array of grains. Acta Mater 2016;112:20-39. doi:10.1016/j.actamat.2016.04.006.

[43] Castelluccio GM, McDowell DL. Microstructure and mesh sensitivities of mesoscale surrogate driving force measures for transgranular fatigue cracks in polycrystals. Mater Sci Eng A 2015;639:626-39. doi:10.1016/j.msea.2015.05.048.

[44] Sauzay M, Liu J, Rachdi F, Signor L, Ghidossi T, Villechaise P. Physically-Based Simulations of the Cyclic Behavior of FCC Polycrystals. Adv Mater Res 2014;891892:833-9. doi:10.4028/www.scientific.net/AMR.891-892.833.

[45] Quey R, Dawson PR, Barbe F. Large-scale 3D random polycrystals for the finite element method: Generation, meshing and remeshing. Comput Methods Appl Mech Eng 2011;200:1729-45. doi:10.1016/j.cma.2011.01.002.

[46] Ghomashchi R, Costin W, Kurji R. Evolution of weld metal microstructure in shielded metal arc welding of X70 HSLA steel with cellulosic electrodes: A case study. Mater Charact 2015;107:317-26. doi:10.1016/j.matchar.2015.07.032.

[47] Boumerzoug Z. Effect of Welding on Microstructure and Mechanical Properties of an Industrial Low Carbon Steel. Engineering 2010;2:502-6. doi:10.4236/engineering.2010.27066. 
[48] Ballesteros AF, Gomes JAP, Bott IS. Corrosion Evaluation of SAW Welded API 5L X-80 Joints in H2S-Containing Solution. Mater Res 2015;18:417-26. doi:10.1590/15161439.368714.

[49] Wu W, Owino J, Al-Ostaz A, Cai L. Applying Periodic Boundary Conditions in Finite Element Analysis. Simulia Community Conf., 2014.

[50] Huang Y. A User-material Subroutine Incroporating Single Crystal Plasticity in the ABAQUS Finite Element Program. 1991.

[51] $\mathrm{Wu}$ T, Bassani J, Laird C. Latent hardening in single crystals I. Theory and experiments. Proc. R. Soc. London A Math. Phys. Eng. Sci., vol. 438, 1991, p. 1-19.

[52] Xie CL, Ghosh S, Groeber M. Modeling Cyclic Deformation of HSLA Steels Using Crystal Plasticity. J Eng Mater Technol 2004;126:339. doi:10.1115/1.1789966.

[53] Siddiq A, Schmauder S. Crystal Plasticity Parameter Identification Procedure for Single Crystalline Material During Deformation. J Comput Appl Mech 2006;7:1-15.

[54] Fong J, Fields R, editors. Basic Questions in Fatigue (Vol. 1). ASTM International; 1988.

[55] Yuan H, Zhang W, Kim J, Liu Y. A nonlinear grain-based fatigue damage model for civil infrastructure under variable amplitude loads. Int J Fatigue 2017;104:389-96. doi:10.1016/j.ijfatigue.2017.07.026.

[56] Fatemi A, Kurath P. Multiaxial Fatigue Life Predictions Under the Influence of meanstresses. J Eng Mater Technol 1988;110:380-8.

[57] Castelluccio GM, McDowell D. Assessment of small fatigue crack growth driving forces in single crystals with and without slip bands. Int J Fract 2012;176:49-64. doi:10.1007/s10704-012-9726-y.

[58] Park J, Nelson D. Evaluation of an energy-based approach and a critical plane approach for predicting constant amplitude multiaxial fatigue life. Int $J$ Fatigue 2000;22:23-9. doi:10.1016/S0142-1123(99)00111-5.

[59] Reis L, Li B, de Freitas M. Crack initiation and growth path under multiaxial fatigue loading in structural steels. Int J Fatigue 2009;31:1660-8. doi:10.1016/j.ijfatigue.2009.01.013. 
2018-03-15

\title{
Microstructure-sensitive estimation of small fatigue crack growth in bridge steel welds
}

\author{
Yuan, Hao
}

\section{Elsevier}

Hao Yuan, Wei Zhang, Gustavo M. Castelluccio, et al. Microstructure-sensitive estimation of small fatigue crack growth in bridge steel welds. International Journal of Fatigue, Volume 112, July 2018, Pages 183-197

https://doi.org/10.1016/j.ijfatigue.2018.03.015

Downloaded from Cranfield Library Services E-Repository 